\title{
REPENSANDO UNA ÉPOCA. APROXIMACIÓN SEMIÓTICA A LOS ESTILOS ALFAREROS DE INICIOS DEL PERÍODO TARDÍO EN YOCAVIL POR MEDIO DEL CASO "LOROHUASI"
}

\section{RETHINKING AN ERA. A SEMIOTIC APPROACH TO EARLY LATE PERIOD POTTERY STYLES IN YOCAVIL THROUGH THE "LOROHUASI" CASE}

\author{
Valeria PalamarczuK* Alina Álvarez \\ LARRAIN $^{* *} \&$ M. SOLANGE GRIMOLDI ** *
}

Se presenta un estudio de los estilos alfareros de inicios del Período Tardío en Yocavil y alrededores, Noroeste Argentino. Enfocándonos en diferentes niveles de contextualización y apelando a herramientas conceptuales de la semiótica y de la psicología de la percepción, comenzamos por el análisis de las ollas "Lorohuasi" - estas integran el conjunto alfarero San José-, para extender las observaciones hacia otras clases de vasijas que comparten ese patrón de diseño. Los mecanismos de abstracción gráfica de seres zoomorfos y antropomorfos identificados revelan el valor de las figuras de la serpiente y del antropomorfo dual en la estética "San José", aspectos que permiten conectarnos con el simbolismo pre-Tardío y con el "santamariano" y que encontramos de gran utilidad para situar esta estética en la historia y el espacio regional.

Palabras clave: Noroeste Argentino, Período Tardío, patrones de diseño, semasiografía, alfarería San José, figuración antropomorfa

This paper presents a study of the ceramic styles of the early Late Period in Yocavil and its environs, in Northwest Argentina. With a multileveled contextual perspective, we employed the conceptual tools of semiotics and the psychology of perception to analyze the "Lorohuasi" pots - part of the San José assemblage- and then expanded our observations to other classes of vessels with the same design pattern. The graphic abstraction of the zoomorphic and anthropomorphic beings that were identified revealed the value of the serpent and dual anthropomorphic figures in San Jose aesthetics, allowing us to make linkages with pre-Late and "Santamariano" symbolism, which was very useful for situating this aesthetic in the region both spatially and historically.

Key words: Northwest Argentina, Late Period, design patterns, semasiography, San José pottery, anthropomorphic representation

\section{INTRODUCCIÓN}

En el marco de nuestras investigaciones relativas a los comienzos del Período Tardío en Yocavil y zonas vecinas en el área valliserrana del Noroeste Argentino, presentamos un avance de nuestro estudio acerca de los estilos alfareros de época. ${ }^{1}$ Nos centramos en observaciones del gran conjunto alfarero "San José", apelando a la valoración de antecedentes y al registro de primera mano de colecciones de museos, de acuerdo con una escala de análisis regional. La indagación en una muestra numerosa fue el primer paso indispensable para reconocer y formalizar diferentes patrones morfológicos y de diseño, los que tomamos como base para un necesario replanteo de las tipologías, largamente relegado (Palamarczuk et al. 2014). Desde un enfoque centrado en diferentes niveles de contextualización (Hodder 1982; Giddens 1995 [1984]) y apelando a herramientas conceptuales de la semiótica (Jackson 2012; Sampson 1985) y de la psicología de la percepción (Arnheim 1985 [1969], 1987 [1957]) encaramos el estudio de los objetos cerámicos, y también de sus contextos de hallazgo y asociaciones materiales, información necesaria para profundizar nuestra reflexión acerca de los aspectos simbólicos de estas alfarerías. Adentrándonos en este

* Valeria Palamarczuk, CONICET, Museo Etnográfico "Juan B. Ambrosetti", Facultad de Filosofía y Letras, Universidad de Buenos Aires, Moreno 350 (1091), CABA, Argentina, email: valepala@yahoo.com.ar

* Alina Álvarez Larrain, Museo Etnográfico "Juan B. Ambrosetti”, Facultad de Filosofía y Letras, Universidad de Buenos Aires, Moreno 350 (1091), CABA, Argentina, email: alinaalvarezlarrain@gmail.com

** Solange Grimoldi, Museo Etnográfico "Juan B. Ambrosetti”, Facultad de Filosofía y Letras, Universidad de Buenos Aires, Moreno 350 (1091), CABA, Argentina, email: solgrimoldi@gmail.com 
complejo universo estilístico exponemos nuestros resultados comenzando por el análisis de un grupo de ollas, llamadas "Lorohuasi", para extender las observaciones hacia otras clases de vasijas que comparten el patrón de diseño de esas ollas. Encontramos en dicho patrón de diseño distintos mecanismos de abstracción gráfica de seres zoomorfos y antropomorfos, que ponen de manifiesto la relevancia de la figura de la serpiente y de la figura humana dual en la estética "San José", aspectos que, sin eclipsar el carácter singular de esas alfarerías, permiten trazar puentes con la estética y el simbolismo "santamariano", propio de momentos más tardíos, y observar las transformaciones en el tema antropomorfo, de gran relevancia desde épocas formativas en la región. ${ }^{2}$

\section{EL PROBLEMA "SAN JOSÉ"}

Hasta la década de 1950, en la literatura arqueológica del Noroeste Argentino se reconocían bajo el nombre de "Andalhuala" o "San José" a un grupo de tinajas funerarias, con o sin representación antropomorfa, diferentes de las "Santa María" (Ambrosetti 1899; Bregante 1926; Bennett et al. 1948; Serrano 1958). En su propuesta de periodificación para el área valliserrana, González (19501955) postuló una posible cultura o Desarrollo Regional San José con una distribución espacial parcialmente superpuesta con áreas de desarrollos posteriores como Sanagasta, Belén y Santa María. Su carácter provisorio obedecía a que estaba representada exclusivamente por hallazgos funerarios de urnas para entierro de infantes y entierros de adultos sin ofrendas; siendo el referente material de la "Cultura San José" la cerámica "San José" y sus contextos funerarios.

Las sistematizaciones más recientes de las alfarerías de inicios del Tardío databan de los años setenta del siglo pasado, cuando a la par que se ampliaba la identificación de tipos cerámicos, comenzaba a revisarse la existencia de una, nunca muy claramente definida, "Cultura San José" o "Hualfín-San José", antecesora de la "Cultura Santa María" en Yocavil (Podestá \& Perrotta 1973; Arena 1975; Perrotta \& Podestá 1975).

En las décadas posteriores paulatinamente la idea de una Cultura San José se fue debilitando y el primer conjunto estilístico se subsumió en el fenómeno santamariano. Este proceso se produjo de la mano del desuso del concepto de cultura en la arqueología de la zona, que fue, de modo heterogéneo, dando paso a conceptos como grupo, pueblo, comunidad, sociedad o formación social. La interrupción de los estudios metódicos respecto de estas alfarerías es un problema que subrayamos para la comprensión de los procesos sociales posteriores al
1000 DC en la zona. Durante décadas han quedado soslayadas las consideraciones relativas a un importantísimo corpus de materiales y, en definitiva, acerca del estatus epistemológico de esta categoría.

En este estado de la cuestión, ¿a qué alude hoy un constructo como el de "San José"? ¿A una cultura, a un estilo alfarero, a un conjunto de estilos alfareros? ¿Tiene sentido mantener esta categoría? Desde nuestra perspectiva sostenemos que puede ser una categoría útil si reelaboramos de modo explícito su definición. Para ello, un paso inicial imprescindible desde un abordaje arqueológico lo constituye el estudio sistemático del universo cerámico que sirvió a su postulación.

Nuestras indagaciones ponen el foco en los estilos alfareros y se centran en la zona de Yocavil y alrededores. Una región en la que los estudios arqueológicos privilegiaron a las sociedades tardías como tema de análisis, pero para la que es necesario avanzar en la discusión del modo en que comenzaron a gestarse los cambios que definen a esta época, tanto desde los aspectos teóricos acerca del cambio social como también desde los estudios de la materialidad.

Plantearemos que San José representa una estética de época -entendida como el conjunto de elementos temáticos y estilísticos que identifican a un autor, movimiento artístico, cultura o época histórica-, propia de los comienzos del Período Tardío, integrada por diferentes estilos alfareros y sus variantes y, en cierto punto, contemporánea a las manifestaciones más tempranas del Estilo Santa María, con la que mantuvo nexos temáticos, tecnológicos y estructurales.

Nuestro estudio de los estilos alfareros pretende contribuir con un problema histórico, situándose en una trama de reflexiones en torno a un escenario poco conocido; los comienzos del segundo milenio en Yocavil y el inicio de procesos de cambio social (ideológicos, políticos, económicos, demográficos) vinculados a la fundación y el crecimiento de poblados conglomerados de tipo pukara que acompañaron una tendencia surandina (Lecoq 1991; Uribe et al. 2004; Scattolin 2006; Arkush 2009). ${ }^{3}$ Sin excluir la existencia de particularidades locales se aprecia un desarrollo conjunto a escala del valle; los poblados poseían estructuraciones y modos constructivos que se reiteran, la funebria se organizaba de acuerdo con pautas semejantes, objetos como bronces, textiles y alfarerías fueron plasmados en estilos compartidos y circularon en el espacio regional evidenciando relaciones de intercambio montadas en lazos parentales y políticos sostenidas más allá de las potenciales situaciones de conflicto endémico (Tarragó 2011).

Las personas que habitaron estos poblados, que diseñaron, elaboraron, usaron e intercambiaron las 
alfarerías que son objeto de nuestro análisis, compartían códigos idiomáticos y visuales, valores éticos y estéticos. Entendemos que las ideas y los valores se sitúan en un contexto material y que las necesidades materiales están situadas en un contexto de normas y expectativas. Entre las múltiples necesidades de los seres sociales están también aquellas vinculadas a la comunicación y a diferentes aspectos de la identidad (Thompson 2000). Estas vasijas, como soporte de diseños particulares, pero entendidas como objetos de significación plena en la unidad que cada una expresa (Caviglia 2002), eran, por tanto, piezas del juego continuo de producción, reproducción y transformación de códigos de comunicación y valores.

\section{CAUSAS Y AZARES EN EL INICIO DE UNA INVESTIGACIÓN}

Entendimos que una de las líneas de análisis para encarar el "problema San José" era comenzar por una revisión del sistema clasificatorio disponible para los estilos alfareros. Para ello diseñamos un estudio a escala regional, basado en el relevamiento de piezas de museos. Nos propusimos elaborar una clasificación que contuviera aquellas variantes establecidas con precisión en los sistemas previos, pero que desestimara las que resultaran ambiguas. Paralelamente se debía formalizar la descripción de variantes no contempladas, y generar un sistema flexible que permitiera reconocer manifestaciones en las que se combinan diferentes patrones o esquemas (Jernigan 1986) de forma o diseño. En definitiva, era necesario reflexionar acerca de la construcción de las unidades de análisis empleadas y respecto del grado de utilidad que estas unidades poseen para abordar los aspectos semióticos en la cerámica, aquello que tiene que ver con los lenguajes visuales.

En marzo de 2008 participamos del rescate de un entierro en las cercanías del poblado de Entre Ríos. La olla contenedora se definía, de acuerdo con la propuesta de Perrotta y Podestá (1975) para las alfarerías "San José", como de Estilo "Lorohuasi", mientras que la tapa -una tinaja rota invertida-, como un ejemplar de lo que las autoras llamaron "tipos intermedios" entre las tinajas "San José Tricolor" y las "Shiquimil Geométrico". En su interior se hallaban los restos de un infante de alrededor de un año (fig. 1) (Álvarez Larrain et al. 2012).

Cuando en los comienzos de nuestra investigación mayor encaramos el estudio de la alfarería de este contexto funerario notamos que las categorías tipológicas disponibles no resultaban completamente satisfactorias. Paralelamente, la función apuntada para estas ollas era la de tapar a urnas San José en entierros de infantes, sin embargo, en nuestro caso, oficiaba de contenedor. ${ }^{4}$

Debemos destacar que la tipología de Perrotta y Podestá se construyó sobre la base de una muestra pequeña de 38 urnas y 55 pucos procedentes de cementerios de la zona de Entre Ríos con exclusividad, por lo que su aplicación a escala regional debe manejarse con precaución. Por su parte, Arena (1975) trabajó con contextos funerarios del Campo del Fraile y alrededores, en el valle del Cajón, construyendo su propuesta tipológica a partir de 32 vasijas de variadas procedencias en los valles de Cajón y Yocavil, con lo que su trabajo posee mayor alcance regional. Su exposición de variantes San José con figuración humana aborda importantes aspectos de la variación estilística y le permiten pensar en situaciones de transición entre San José y Santa María, elementos que retomaremos avanzando la exposición. ${ }^{5}$

En cierto modo, el estudio de los materiales de este rescate nos llevó a rastrear, como meta inicial, otros ejemplares de morfología y diseños similares al de las llamadas ollas "Lorohuasi". En este trabajo haremos un recorte del universo San José para exponer en primer término nuestro estudio de dichas ollas. Luego ampliamos la exposición hacia otros ejemplares de morfología similar y patrón de diseño diferente y a la inversa, de similar patrón de diseño en distintas formas de vasijas. Como veremos, este último camino mostró las más interesantes derivaciones.

\section{LOS CONCEPTOS Y LOS MÉTODOS}

Como premisa fundamental para el trabajo consideramos que la estética San José integró los dispositivos comunicacionales e identitarios de los grupos sociales en una extensa región por medio de recursos visuales de transmisión de información dependientes del contexto de la enunciación; su decodificación requirió de la participación de observadores informados respecto de las convenciones que pautan significados a los signos manejados.

Hace ya algunas décadas, la arqueología ha recurrido a la semiología de base "saussureana" y a la semiótica de raíz "peirceana” (Hodder 1982; Preucel \& Bauer 2001), principalmente para el estudio de las imágenes visuales plasmadas en distintos soportes de la cultura material dentro de sociedades carentes de escritura, como, por ejemplo, en el arte rupestre (Llamazares 1989; Rocchietti 2009; Martel \& Giraudo 2014), los textiles (Cereceda 1990, 2010) y la cerámica (Balesta 2000; Wynveldt 2007), entre otros. 

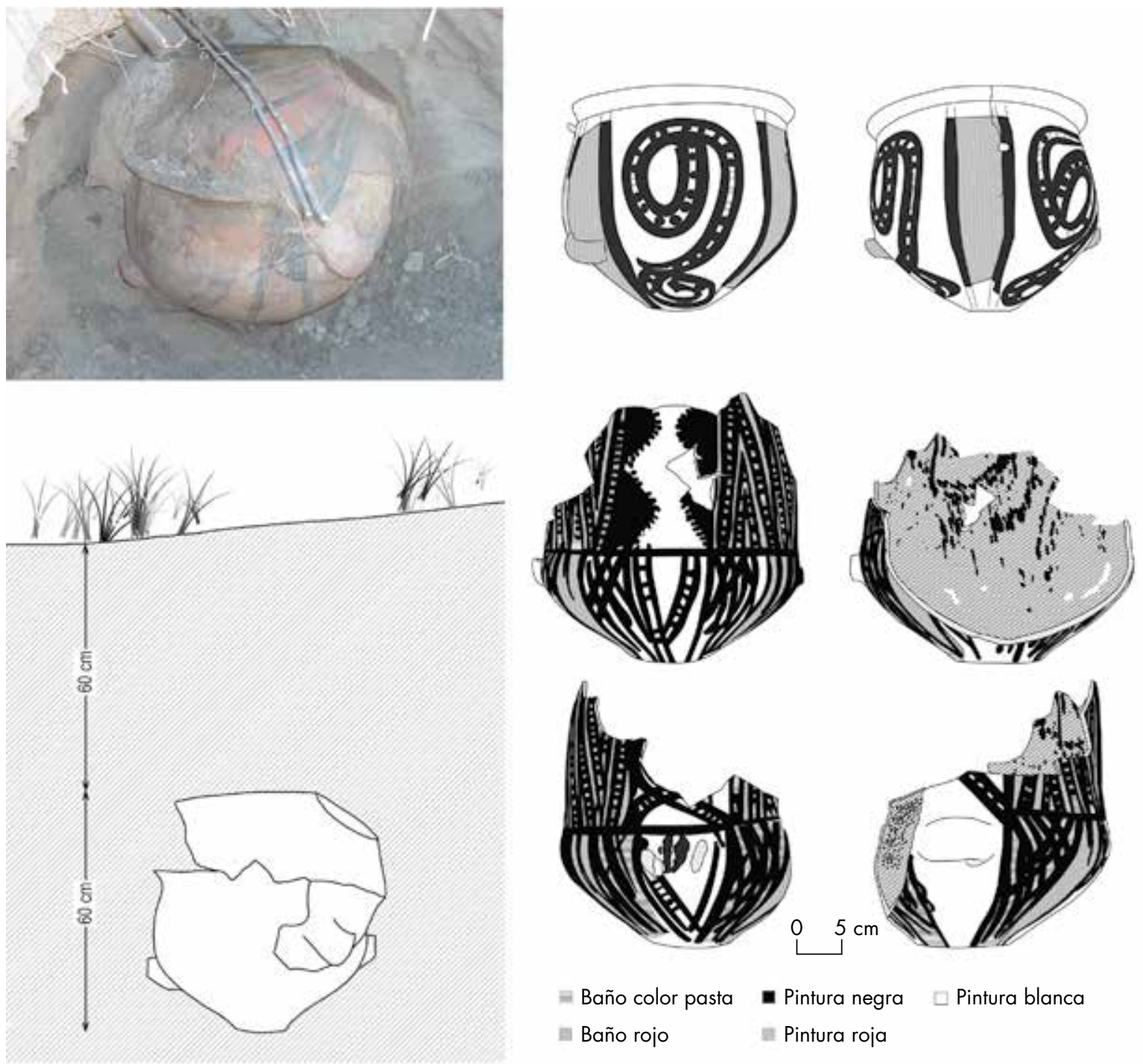

Figura 1. Hallazgo fortuito de un entierro de infante en olla Lorohuasi en las cercanías del pueblo de Entre Ríos, valle de Yocavil, Catamarca, Argentina.

Figure 1. Chance discovery of an infant entombed in a Lorohuasi pot near Entre Ríos village, Yocavil Valley, Catamarca, Argentina.

En esta línea de indagaciones respecto de los lenguajes visuales, acudimos aquí al concepto de semasiografía o sistema semasiográfico para pensar en los mecanismos de funcionamiento y organización del comportamiento gráfico materializado en las vasijas. El concepto refiere a grafismos que no se relacionan directamente con el habla, motivo por el cual suele no considerárselos como escritura en un sentido estricto (Sampson 1985; Jackson 2012). ${ }^{6}$ Estos grafismos se estructuran de acuerdo con lógicas de diseño reguladas y contienen significados socialmente pautados, los mensajes pueden "traducirse" o expresarse en un lenguaje hablado aunque no palabra por palabra. Igual que otros sistemas gráficos, los sistemas semasiográficos pueden integrar elementos no miméticos o convencionales, es decir, que los signos que lo componen poseen una codificación arbitraria, como también elementos miméticos, motivados o icónicos, cuando media alguna relación de similaridad entre imagen y referente. Claro está que esta clase de distinción resulta en ocasiones problemática y podría decirse que remite a gradientes más que a situaciones absolutas (Arnheim 1985 [1969]; Sampson 1985; Preucel \& Bauer 2001; Jackson 2012). Esta distinción nos resulta útil para abordar el tema del carácter abstracto en las representaciones de la alfarería. 
Concebir al lenguaje y a los sistemas de signos como el resultado de procesos históricos implica la noción de dinamismo en los sistemas. Dentro de estos sistemas puede haber diferentes fuerzas conservadoras que aíslan a los signos del cambio arbitrario (Saussure 1984 [1913]); a pesar de ellas, estos se modifican con el tiempo, según ritmos y necesidades variables. A veces esos cambios son drásticos, otras graduales y sutiles. El cambio de las formas gráficas resulta para nosotros, desde una perspectiva arqueológica, más fácil de apreciar que el cambio de los significados asociados. Es posible preguntarse entonces en qué medida los significados de los signos que estamos estudiando se mantuvieron invariantes y de qué manera fueron cambiando en diferentes escenarios espacio-temporales. Los significados de los signos, además de variar en el tiempo, pueden también ser múltiples en un plano sincrónico, una característica que pone de relieve la importancia que adquiere la situación de la comunicación en la apreciación de significados. Los diferentes contextos en los cuales las vasijas cumplían roles también pudieron introducir distinciones semánticas, pues el significado de los signos no solo está dado por las relaciones con otros signos en una enunciación y dentro del sistema semiótico, sino también por el contexto social de su uso (Voloshinov 1976). Las investigaciones arqueológicas encuentran por lo general graves límites a la hora de reconocer y comprender los diferentes contextos sociales de uso de los sistemas simbólicos, en qué medida los diferentes actores sociales eran más o menos competentes en cuanto al manejo y la reproducción del sistema, en qué medida se jugaban disputas sociales por medio de su uso, de qué múltiples maneras podían "leerse" los elementos del sistema fuera de la comunidad semiótica. Nos preguntamos también acerca del valor relativo de cada signo, determinado por el propio sentido y por el contraste con otros signos que integran el sistema, dentro de los contextos de la representación semasiográfica. ${ }^{7}$

Apelamos a una descripción minuciosa de las vasijas y de sus diseños para analizar la manera particular en que el sistema gráfico se organiza en la estética San José. Para este ejercicio nos basamos en los principios de la psicología de la percepción aplicados al análisis de las manifestaciones visuales (también conocidos como teoría de la forma o Gestalt). Estos plantean un interjuego entre los mecanismos mentales de la percepción, la forma de la imagen (su color, textura, contrastes, posición, equilibrio, proporción, tamaño, composición, etc., entendidos como partes de una totalidad) y la captación de estructuras de significados. Se reconoce así la existencia de elementos objetivos y subjetivos en la experiencia de la observación, la que resulta tanto de las propiedades del objeto como de la naturaleza del sujeto observador (Arnheim 1985 [1969], 1987 [1957]). Este tipo de aproximación al análisis de las manifestaciones visuales prehispánicas en el ámbito del Noroeste Argentino fue considerado de manera pionera por Caviglia (1985) y ha sido recientemente revalorizado (por ejemplo, Puente \& Quiroga 2007; Ávila 2008, 2011).

Apelamos también a las sucesivas escalas de análisis de los contextos arqueológicos para considerar diferentes escenarios espacio-temporales y funcionales en los que intervinieron las vasijas y, por tanto, fueron empleadas consciente o inconscientemente en situaciones comunicacionales.

La metodología para el registro y el estudio de las piezas se basa en tres pilares; el primero es la conceptualización del estilo alfarero como un punto de convergencia entre aspectos tecnológicos, morfológicos y de diseño. El segundo, la observación de la mayor cantidad de piezas posibles para captar lo regular y lo excepcional en cada uno de estos aspectos como requisito para identificar y describir patrones o esquemas que permitan agrupar piezas por sus semejanzas (Caviglia 2002; Wynveldt 2007; Cereceda 2010). El tercero, un juego continuo de ida y vuelta entre diferentes escalas de análisis: de las características intrínsecas de las vasijas a la identificación de patrones compartidos entre varias, de la vasija como unidad a su desempeño en contextos específicos y sus asociaciones materiales en contextos arqueológicos, de la escala del hallazgo puntual a la de sitio, localidad y región (Palamarczuk 2011).

El estilo es nuestra unidad de análisis y cada vasija una unidad de observación. Los pasos del trabajo incluyen el relevamiento fotográfico, morfológico, métrico y de los diseños de las vasijas, así como el estudio de marcas de uso y asociaciones apelando al soporte documental de las colecciones. Empleamos el sistema de clasificación morfológica a partir del contorno de las vasijas, considerando la ubicación de puntos característicos, la geometría de las formas, sus proporciones y simetría (Shepard 1957). De ese modo identificamos el stock de formas presentes, las cuales se ilustraron y agruparon en conjuntos mayores (ollas, tinajas y pucos).

Dentro de las variables tecnológicas consideramos aspectos macroscópicos como la técnica de modelado, atmósfera de cocción, tipos de bases y tipos de asas.

Las superficies interna y externa son el campo tridimensional complejo en donde se plasmaron los grafismos en un juego de mutua relación diseño-forma. En la descripción de los diseños distinguimos las técnicas empleadas (modelado, pintura aplicada por baños, con pinceles, por salpicado), los colores y su secuencia de aplicación. En su análisis buscamos identificar esquemas 
o repeticiones entre vasijas en diferentes aspectos de la producción del diseño, como la estructuración de los campos, los temas apelados, los modos de representación particulares, los motivos o unidades de diseño y sus composiciones (arreglo espacial) en cada campo (Levine 1957). Sobre la base de las recurrencias de estos aspectos en un conjunto de vasijas formalizamos diferentes patrones de diseño.

Para el estudio de los contextos de hallazgo se tuvieron en cuenta dos aspectos: la dimensión espacial a nivel de procedencias y la reconstrucción de contextos y asociaciones. Para abordar el primer punto elaboramos mapas de distribución regional y frecuencias de los patrones de diseño mediante SIG. Para el segundo punto se trabajó con la documentación de colecciones. La distribución espacial de las vasijas -en diferentes escalas- constituye una de las facetas del paisaje socialmente construido. Los escenarios en los que se las utilizó y depositó quedaron marcados por los significados -múltiples y cambiantesasociados a las mismas.

El apoyo de la descripción y del análisis en fotografías, figuras y mapas es un requisito metodológico importante para la transposición de nuestras reflexiones acerca del modo en que se articulan las diferentes técnicas y repertorios en vasijas singulares y en el conjunto de piezas que integran un sistema.

\section{LA MUESTRA Y SU ESTUDIO}

Hemos trabajado con colecciones de museos e incluido algunas piezas publicadas. Las vasijas ingresadas a la base de datos hasta el momento son $311 .^{8}$ Entre ellas distinguimos 23 vasijas que corresponden por forma $y$ diseño a las ollas "Lorohuasi" (Anexo 1). ${ }^{9}$
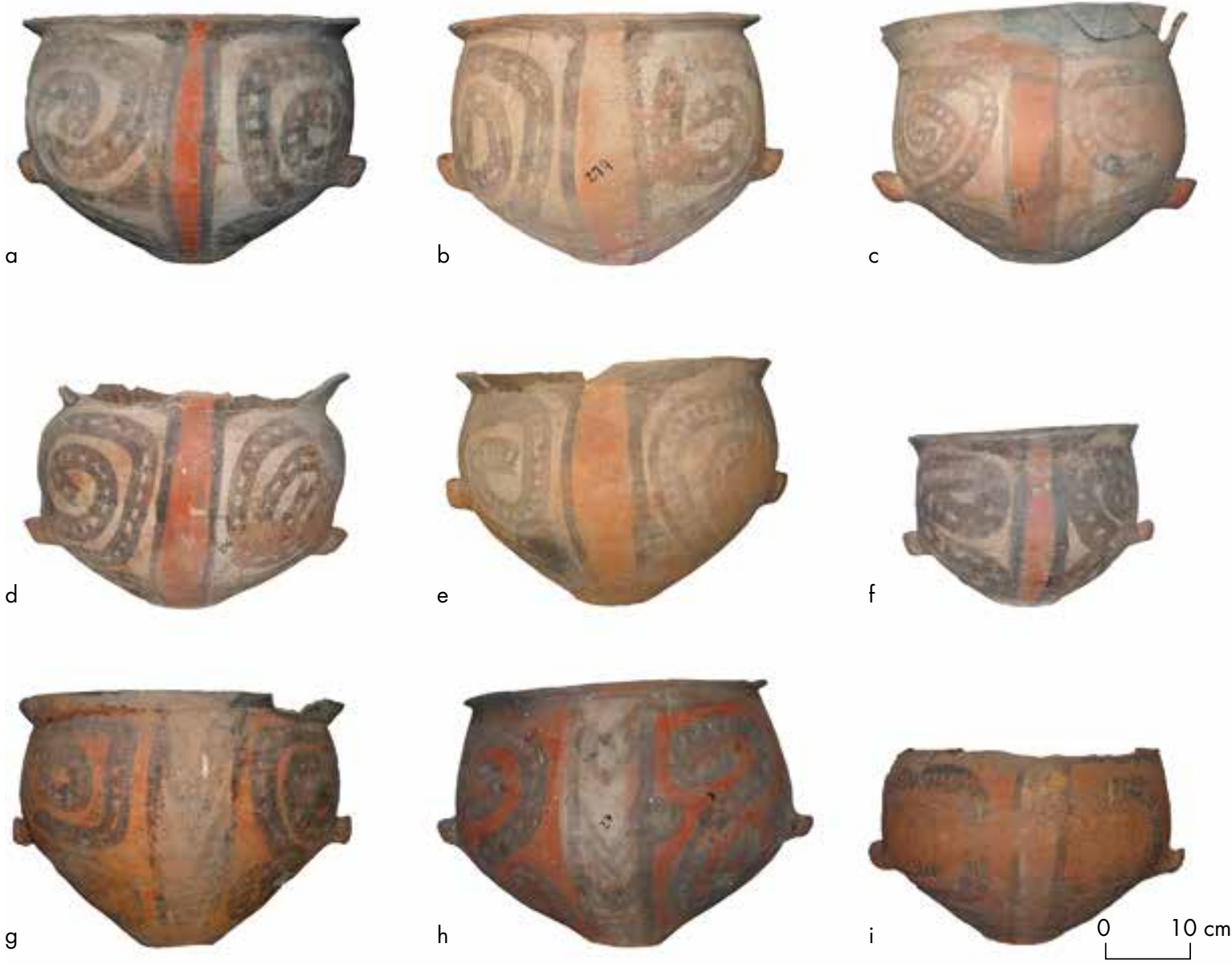

Figura 2. Ejemplos de ollas "Lorohuasi" que integran la muestra estudiada: a) MLP-Ar-6973 BMB; b) MEB 279; c) MLP-Ar-5828 BMB; d) MEB 276; e) MLP-Ar-6293 BMB; f) MEB 110; g) MEB 272; h) MEB 277; i) MEB 43 CB.

Figure 2. Examples of Lorohuasi pots in the sample: a) MLP-Ar-6973 BMB; b) MEB 279; c) MLP-Ar-5828 BMB; d) MEB 276; e) MLP-Ar-6293 $B M B$; f) $M E B$ 110; g) MEB 272; h) MEB 277; i) $M E B 43$ CB. 
Son piezas de porte mediano con alturas entre 18 y $35 \mathrm{~cm}$ y diámetros máximos del cuerpo entre 26 y 43 $\mathrm{cm} .{ }^{10}$ Las bases son siempre cóncavo-convexas, de perfil continuo o inflexionado. Las asas son pares, horizontales, de sección subrectangular y en menor medida suboval, poseen inserción por remaches y se ubican por debajo o a la altura del punto de tangencia vertical. El contorno en sección longitudinal más frecuente del cuerpo es el ovaloide, con algunas variantes. La mayoría de estas ollas presenta un leve achatamiento antero posterior, siendo los diámetros entre asas mayores que aquellos entre las caras frontales. El borde es evertido recto y el labio con tendencia a ser recto o redondeado (fig. 2).

A partir de este conjunto de ollas formalizamos un patrón de diseño -al que llamamos Lorobuasi por extensión del nombre tradicional de estas ollas-, con una estructuración cuatripartita en el que domina una lectura por planos del diseño pintado en campos de registro vertical sobre la superficie externa. Llamamos campos del cuerpo a los espacios más amplios de diseño y bandas a los espacios más estrechos que actúan dividiendo campos y a la vez pueden contener motivos. Las bandas ocupan una disposición central en los frentes y laterales de la vasija (fig. 3).

El diseño pintado es polícromo. El contraste tonal se establece entre tres colores: blanco, negro y rojo. En ocasiones se suma el color de fondo anaranjado de la pasta cerámica, producto de una cocción oxidante. En las bandas vemos siempre un color contrastante respecto del fondo de los campos mayores, si los campos son de fondo rojo, las bandas son blancas y viceversa. Cuando la banda es de fondo rojo no contiene diseños, si, en
OLLA "LOROHUASI"

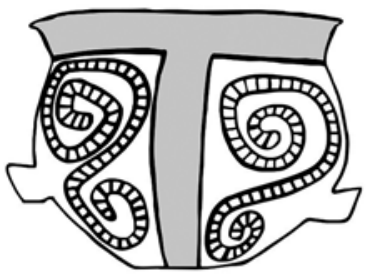

FORMA

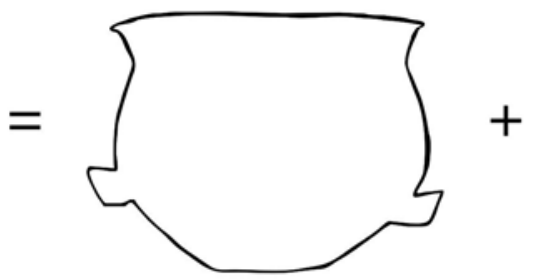

PATRÓN

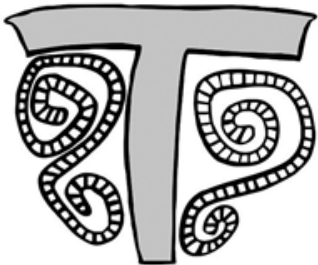

a

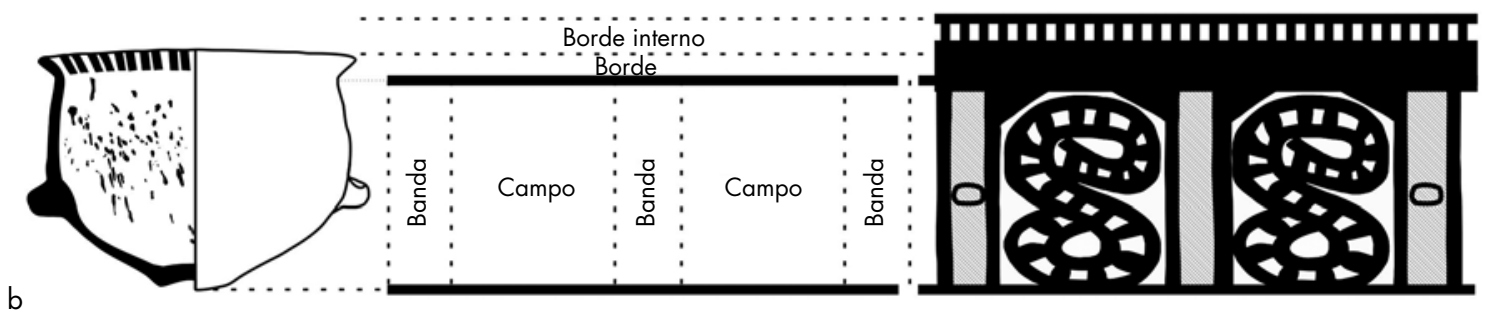

ESTRUCTURA DEL DISEÑO CUATRIPARTITA VERTICAL A

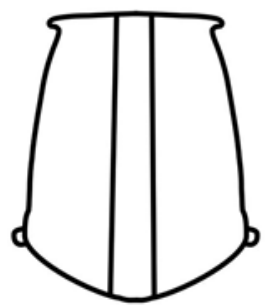

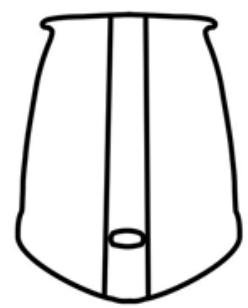

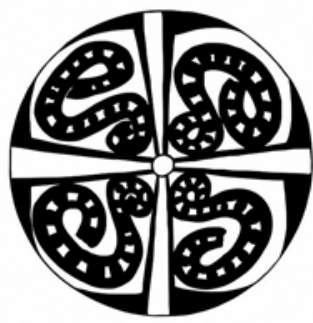

d

Figura 3. Forma, estructura y composición del diseño en las ollas Lorohuasi: a) Ollas Lorohuasi como conjunción de forma y patrón de diseño; b) campos de diseño y ejemplo de esquema de diseño interior y exterior en proyección "cilíndrica"; c) estructura del diseño; d) proyección "cónica simple" del diseño.

Figure 3. Form, structure and design composition of Lorohuasi pots: a) Lorohuasi pots as a conjunction of form and design pattern; b) design fields and example of interior and exterior design scheme in "cylindrical" projection; c) design structure; d) "simple conical" projection of the design. 
cambio, es de fondo blanco, puede o no contener diseños, que consisten en chevrons de cordón punteado o rayado, siempre con sus ápices apuntando hacia abajo y un caso que presenta dos medias "S" de cordón rayado en las bandas laterales.

Los límites entre bandas y campos están definidos por una línea negra, los colores blanco y rojo no toman contacto directo, siempre se interpone un trazo negro, que es también el color elegido para delinear los motivos. En los campos del cuerpo se repite con insistencia un diseño singular en forma de "S". La ubicación del motivo es central, su posición vertical y su tamaño grande, ocupando todo el campo. Su trazo es doble, con rayas perpendiculares o línea de puntos en la franja interior (cordón rayado o punteado). En ocasiones la composición incluye triángulos plenos o con cordones rayados o punteados, con sus vértices, a veces rectos y otras curvos, penetrando en los sectores que el diseño de la "S" deja libres. El motivo de la "S" en la alfarería San José y Santa María se vincula con el tema de la serpiente, un elemento persistente, de marcado simbolismo durante el Tardío regional. El modo de representación es muy constante, posee cierto carácter motivado o icónico dado por la estilización de un cuerpo segmentado -como el que presenta la serpiente coral y falsa coral- con una sinuosidad que denota movimiento y una proyección "desde arriba". Pero también plantea un interesante grado de abstracción por medio de la ausencia de la representación de la cabeza.

Las pinceladas negras son gruesas, con variaciones entre 0,8 y $2,2 \mathrm{~cm}$, y se aprecia el empleo de pincel doble o de dos pinceles manipulados con la misma mano para generar diseños de líneas paralelas en un único ademán. La secuencia de aplicación de baños y pinturas presenta variantes, observándose baños totales de las superficies, o solo de los campos. También hay casos en los que se pintaron los motivos en negro sobre un fondo del color de la pasta y luego se pintó en rojo su espacio externo, asemejando un diseño negro sobre rojo.

Debido a las proporciones de la forma, la disposición de las bandas, las dimensiones equivalentes de los campos de diseño y la centralidad de la figura de la "S" vertical, el diseño externo adquiere un carácter de notable equilibrio. La simetría de campos del cuerpo más frecuente es la traslación, habiendo en algunos ejemplares campos que se repiten por reflexión y en otros ejemplares una combinación de ambas clases de simetría, aspecto que disminuye el equilibrio cuando observamos la pieza completa.

Otros espacios de diseño son el sector interno del borde, donde se trazaron líneas radiales simples o dobles; el labio, que posee un trazo negro pleno, y la superficie interna del cuerpo, donde puede haber baño rojo, del color de la pasta o blanco, junto con chorreaduras y salpicaduras de pintura negra. Las chorreaduras corresponden a desprolijidades en el trazo del diseño del borde, mientras que las salpicaduras son buscadas intencionalmente, configurando un diseño dinámico y caótico que trasunta el movimiento de sacudir el pincel. Por último, varias piezas poseen baños y trazos negros desprolijos en la superficie cóncava externa de la base (fig. 4).

De los 23 ejemplares de ollas Lorohuasi solo nueve tienen procedencia conocida: Fuerte Quemado (2), Las Mojarras (1), Caspinchango (1), Entre Ríos (2), Lorohuasi (2) y Santa María (1), estando presentes en ambas bandas del sector centro-sur del valle de Yocavil. La funcionalidad de todos los ejemplares registrados es funeraria, principalmente como tapa, pero también como contenedor en entierros de infantes. En solo un caso se identificó un piqueteado en el fondo de la base, compatible con un uso previo, posiblemente no funerario.

Una vez que tomamos "conciencia" de los rasgos distintivos del patrón Lorohuasi, avanzamos en múltiples direcciones. Por un lado, buscando ejemplares de morfología similar a las ollas Lorohuasi, pero con diferentes diseños; por el otro, buscando reconocer el patrón de diseño Lorohuasi en otras morfologías. Así vimos que esa forma admitía otras variantes de diseño, aunque representadas por escasos ejemplares (siete) (fig. 5). ${ }^{11}$

En paralelo, fue asombroso reconocer el patrón de diseño en una multiplicidad de formas insospechadas (fig. 6); se registraron 13 grupos morfológicos representados por 71 ejemplares, entre tinajas, pucos y ollas de diverso contorno y dimensiones (fig. 7) (Anexo 2). Estos fueron hallazgos muy reveladores en varios aspectos. $\mathrm{Si}$ en la forma olla la figuración es pintada y remite casi con exclusividad al tema de la serpiente, vemos que la forma puco admite en simultáneo al modelado zoomorfo y que las tinajas admiten al modelado antropomorfo dual; con cejas-nariz, ojos, boca, orejas y ¿manos? en ambos frentes (figs. 8 y 9). El contexto de las referencias se amplía y nos lleva a reconsiderar apreciaciones basadas en la descripción de las ollas con independencia del conjunto mayor de vasijas que comparten un mismo patrón de diseño.

\section{LA HUMANIDAD Y LA ANIMALIDAD FIGURADAS Y LA ABSTRACCIÓN PERCEPTUAL}

El reconocimiento del patrón Lorohuasi en otras formas presenta facetas interesantes para el análisis de los significados que las vasijas manifiestan. Pudimos identificar 
a
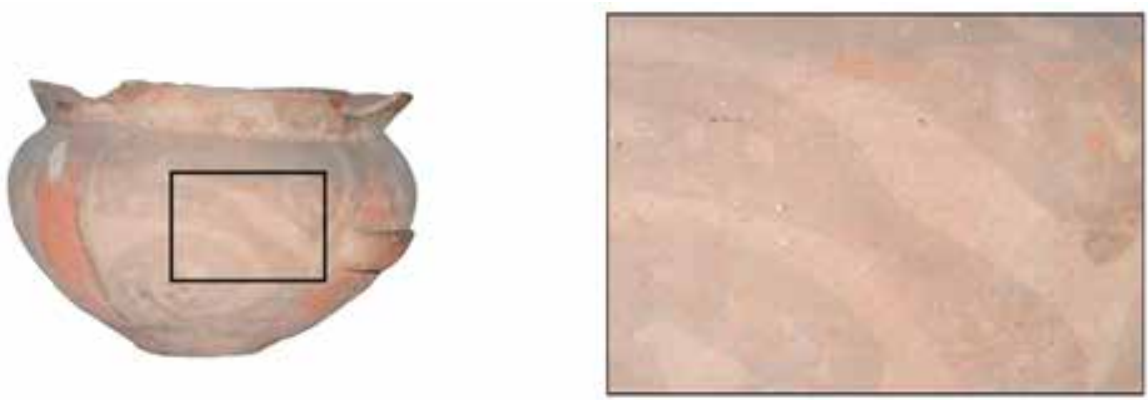

b
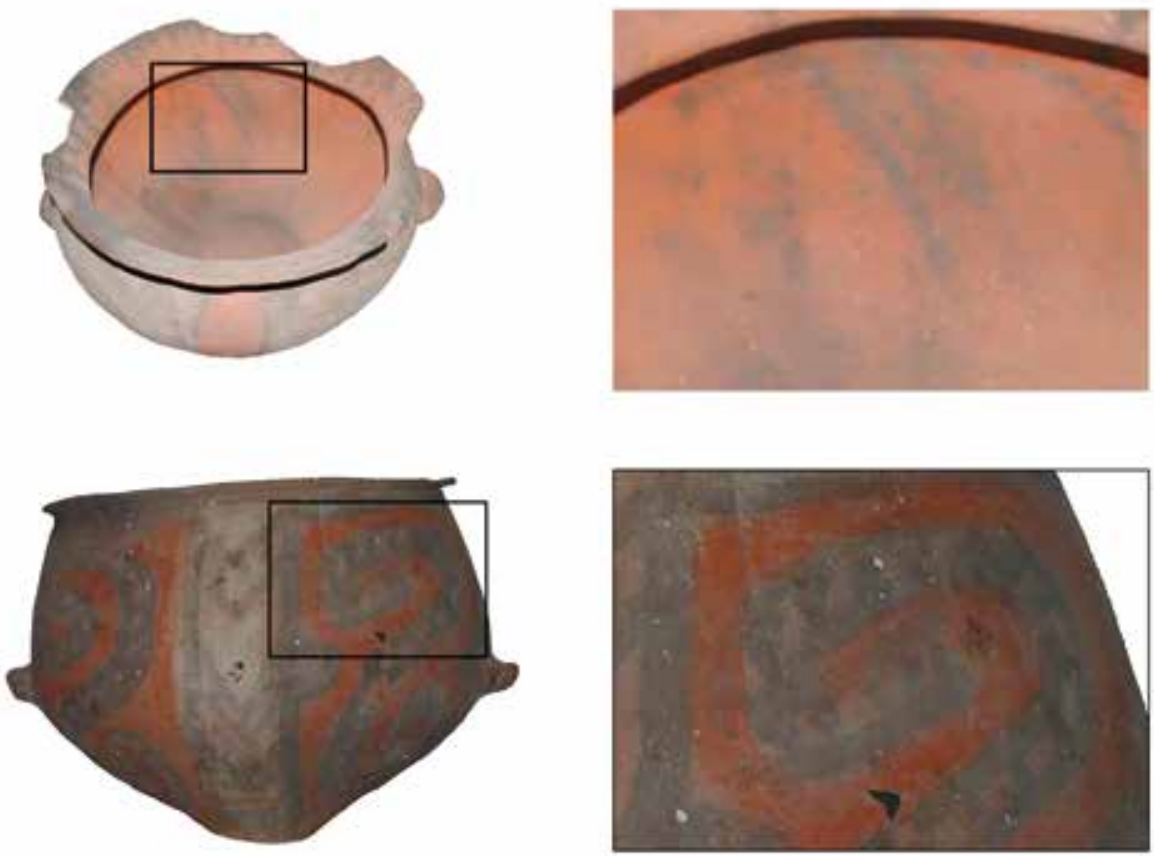

\section{C}
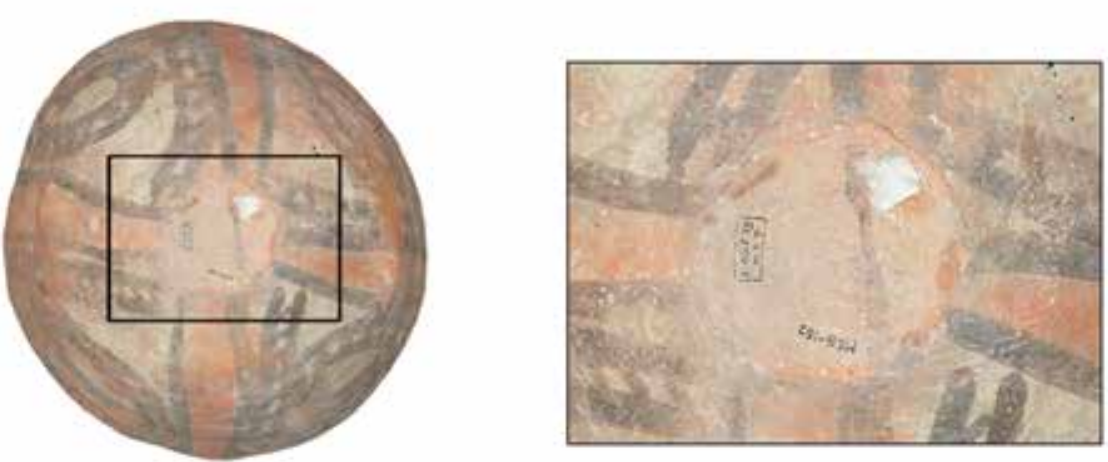

Figura 4. Detalles de opciones técnicas y compositivas: a) Uso de un pincel doble evidenciado por el cruce de líneas accidental (MEJBA$31555)$; b) salpicado intencional en la superficie interna (MEJBA-31555); c) aplicación final de pintura roja por fuera del motivo pintado en negro (MEB 277); d) empleo ocasional de la superficie externa de la base como un campo de diseño (MEB 217).

Figure 4. Detail of technical and compositional options employed in Lorohuasi pot design: a) Use of a double brush as evidenced by accidental line crossing (MEJBA-31555); b) intentional splashing on the inner surface (MEJBA-31555); c) final application of red paint outside of the black painted motif (MEB 277); d) occasional use of the outer surface of the base as a design field (MEB 217). 

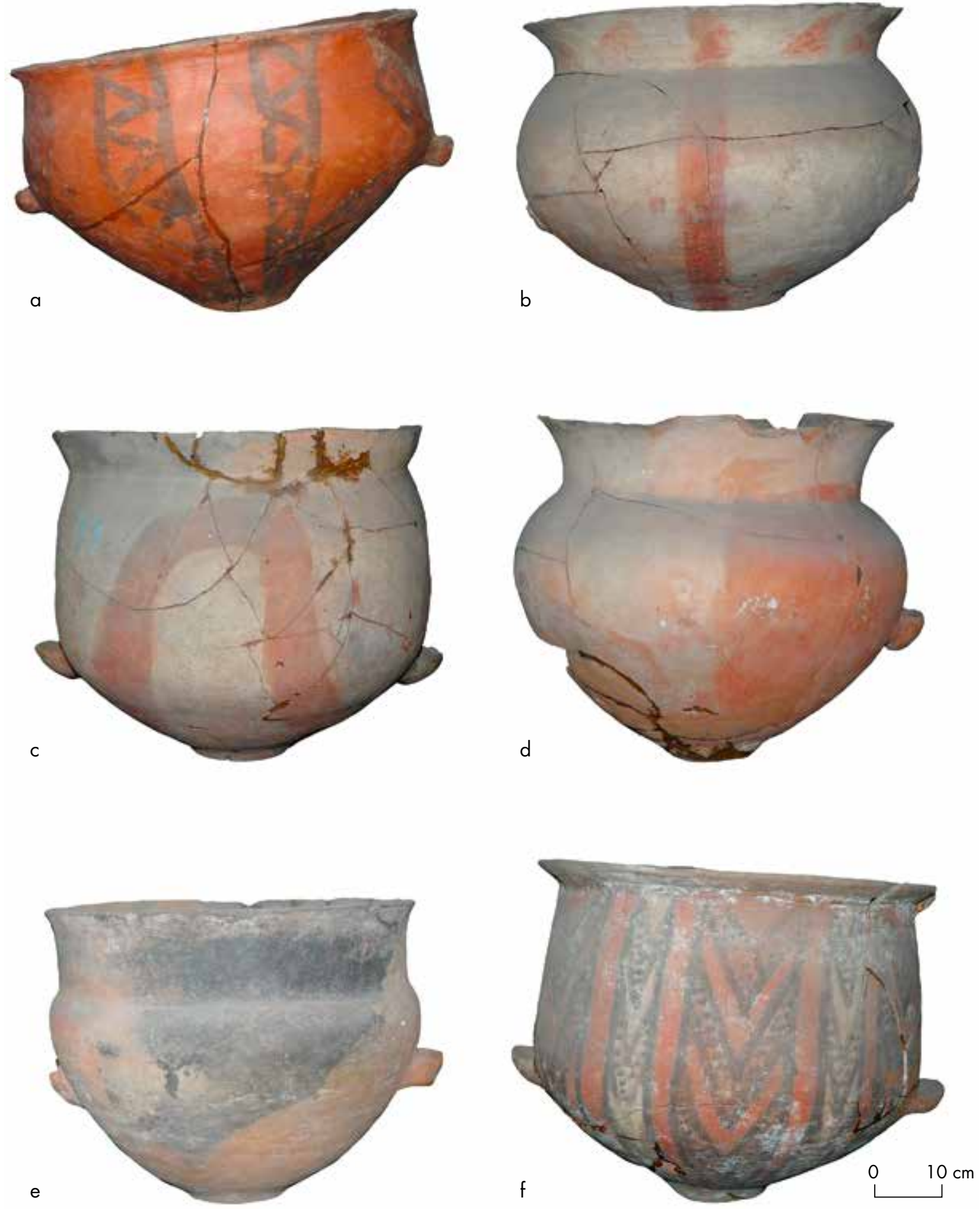

Figura 5. Ejemplos de ollas con morfología afín a las Lorohuasi, pero con diferencias en los diseños: a) MLP-Ar-2685 FPM; b) MLP-Ar-6026 BMB; c) MLP-Ar-5829 BMB; d) MLP-Ar-5861-BMB; e) MLP-Ar-5433-BMB; f) MLP-Ar-5056-BMB.

Figure 5. Examples of pots morphologically similar to the Lorohuasi pots, but displaying differences in design: a) MLP-Ar-2685 FPM; b) $M L P-A r-6026$ BMB; c) MLP-Ar-5829 BMB; d) MLP-Ar-5861-BMB; e) MLP-Ar-5433-BMB; f) MLP-Ar-5056-BMB. 
Ollas con borde (A1)

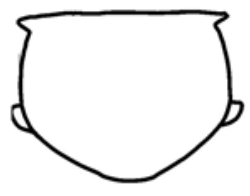

MEB 279

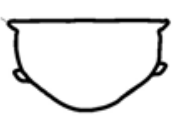

Pucos con punto angular (B1)

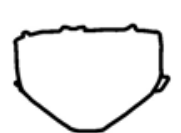

MEB 5450
MEJBA - 4270 -

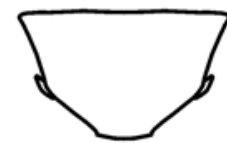

MEJBA - SIN NÚMERO

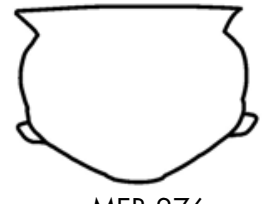

MEB 276

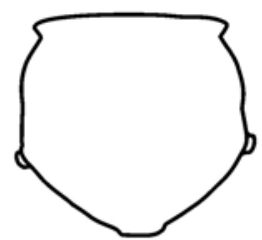

BMB 5194
Olla simple (A4)
Pucos de contorno simple (B2)

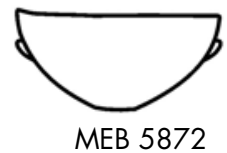

Tinajas subcónicas (C3)

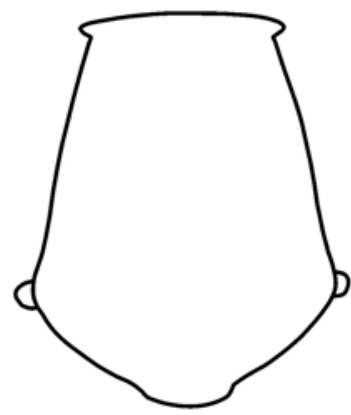

MEJBA 44-1891

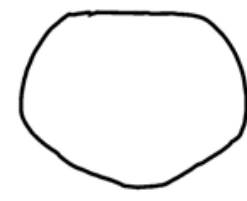

MEJBA 36-652
Tinajas ovaloides (C2)

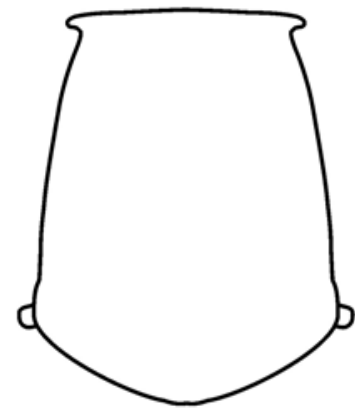

MEJBA 76-306

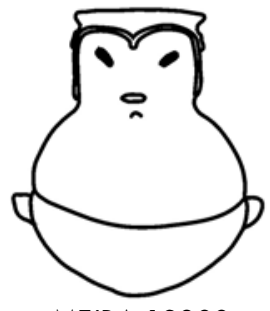

MEJBA 12388

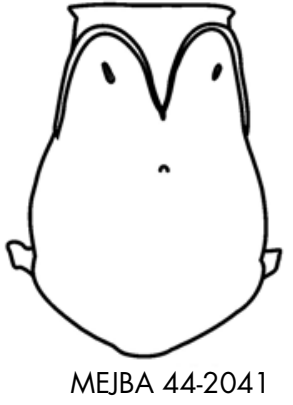

L

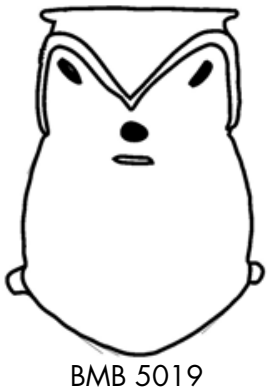

$40 \mathrm{~cm}$
Tinaja con cuello $(\mathrm{C} 1)$

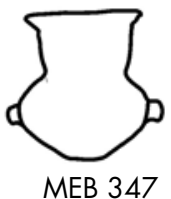

Tinajas antropomorfas (D1)

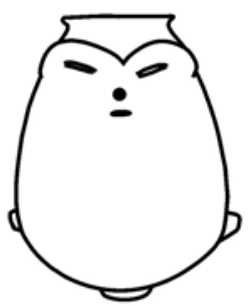

PIEZA EN EXPOSICIÓN MUSEO JULIO MARC

Tinajas antropomorfas con cuello (D2)

Figura 6. Formas que admiten el patrón de diseño Lorohuasi. Clasificación por grupos morfológicos.

Figure 6. Classification of forms that support the Lorohuasi design pattern. 


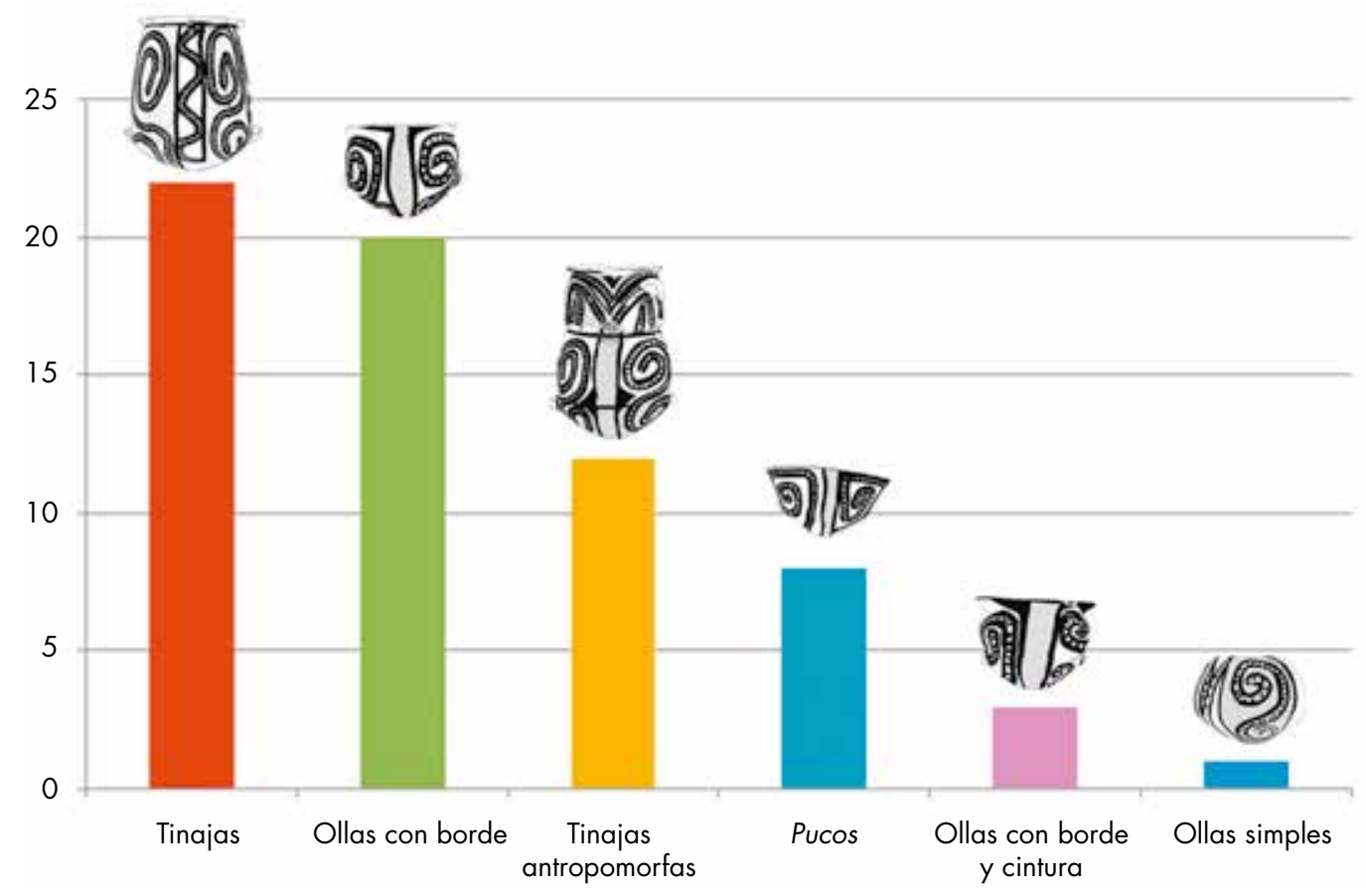

Figura 7. Frecuencia de los grupos morfológicos con patrón de diseño Lorohuasi.

Figure 7. Frequency of morphological groups with the Lorobuasi design pattern.

algunos rasgos propios de los grupos morfológicos que aportan ingredientes para esa reflexión (figs. 10 a 13) (Anexos 3 y 4).

Los diferentes modelos de tinajas y ollas con cintura contienen en los campos del cuerpo composiciones variadas que mantienen a la " $\mathrm{S}$ " como motivo central, mientras que en las bandas se amplió sensiblemente el stock de motivos pintados, en muchos casos con alternancia de motivos entre bandas centrales y laterales. Al igual que en las ollas los diseños del interior de la pieza son de líneas paralelas en borde y salpicaduras en el cuerpo. En las tinajas sin figuración modelada predominan las bandas blancas y los campos de fondo rojo, mientras que en las modeladas (antropomorfas) la relación entre colores de fondo es más pareja. ${ }^{12}$

Las técnicas de diseño incluyen en muchos casos el modelado de rasgos del rostro humano en la parte superior. En ellos, la vasija como totalidad representa una figura antropomorfa en postura vertical, con sendos rostros opuestos en cada frente de la vasija, compartiendo un mismo cuerpo y orejas. El espacio que ocupa el diseño patrón Lorohuasi en estos casos correspondería al cuerpo del personaje y su vestimenta. Variantes descritas por Arena (1975), como Peñas Azules Tricolor, Grupo X y Grupo Y, estructuran el cuerpo de la vasija de acuerdo con el patrón Lorohuasi en el sector que toca a la representación del cuerpo-atuendo del personaje, pudiendo agregarse un cuello que introduce la noción de tripartición de la vasija; típica del universo de representaciones Santa María. En algunas de estas tinajas inclusive existe una notable semejanza morfológica entre el contorno del cuerpo con el contorno de las ollas sin modelado.

Entre las tinajas 16 (42\%) presentan modelado antropomorfo. El conocer estos modelos nos exige una nueva mirada sobre aquellas tinajas que no poseen modelado. Nuestro incompleto acercamiento al sistema de signos abordado nos permite no obstante hilvanar relaciones asociativas o "paradigmáticas" entre los signos, por lo que podríamos ahora notar en las segundas un proceso de abstracción de la figura humana relacionado con un recurso de metonimia. Se advierte que una cosa puede tener muchas facetas y se percibe cada aspecto parcial como una aparición de la totalidad. Se percibe el cuerpo con patrón de diseño Lorohuasi y se obtiene una referencia (renvois sensu Arnheim 1985 [1969]) que apunta más allá del aspecto dado, hacia otros aspectos adyacentes o subsiguientes en otros modelos conocidos, a partir de ella se conecta con la idea de la figura humana.

Por su parte, en los pucos los campos son blancos y las bandas rojas. ${ }^{13}$ Las distintas formas de las vasijas proveen superficies tridimensionales particulares, por sus accidentes y dimensiones, que entran en juego con 

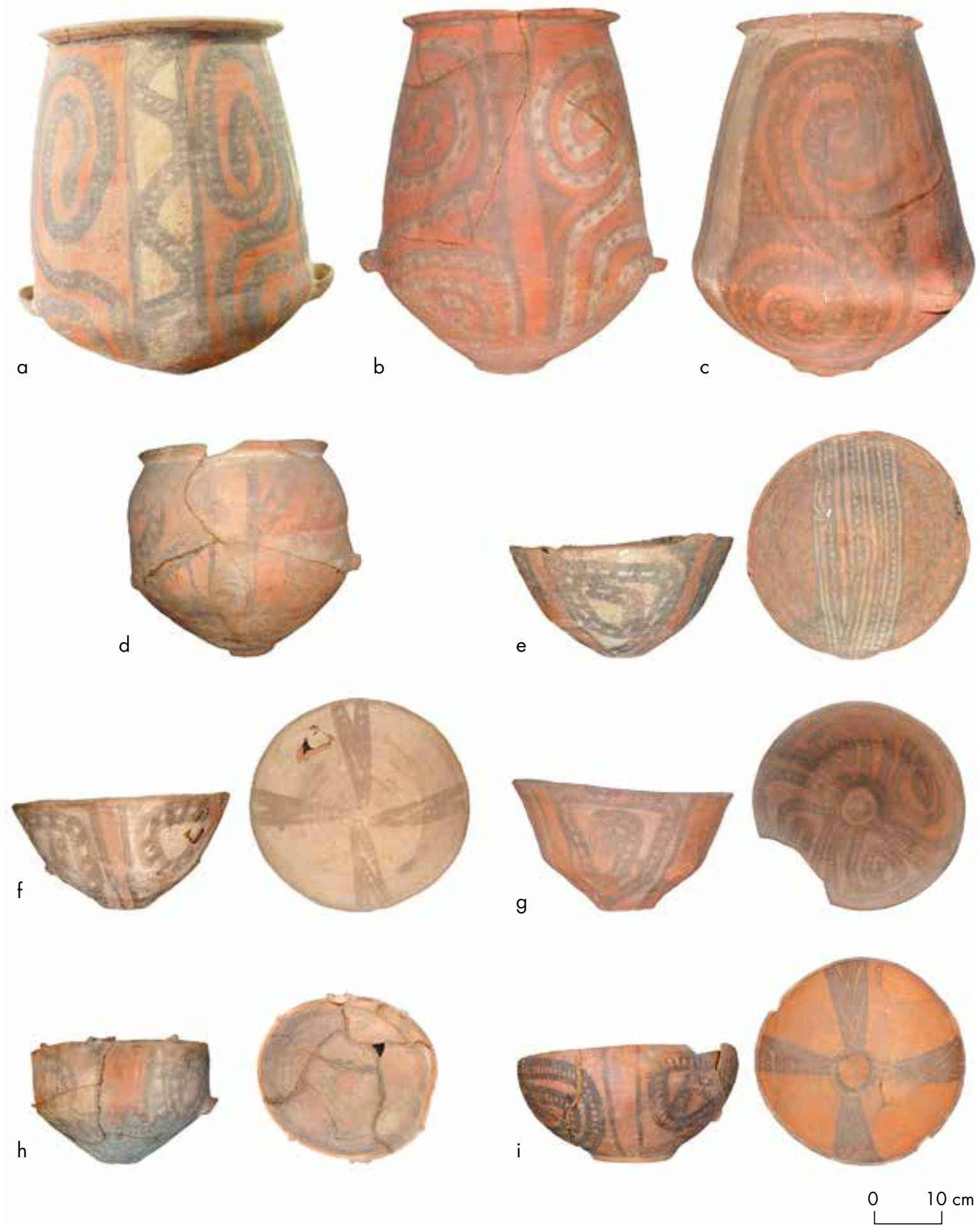

Figura 8. Ejemplos de tinajas y pucos con patrón de diseño Lorohuasi: a) MEB 205 CB; b) MEJBA-029056; c) MEJBA 44-1891; d) MLP-Ar5194 BMB; e) MEB 217; f) MLP-Ar-5221 BMB; g) MEJBA-31670; h) MLP-Ar-5450 BMB; i) MLP-Ar-5894 BMB.

Figure 8. Examples of jars and bowls with the Lorohuasi design pattern: a) MEB 205 CB; b) MEJBA-O29056; c) MEJBA 44-1891; d) MLP$A r-5194$ BMB; e) MEB 217; f) MLP-Ar-5221 BMB; g) MEJBA-31670; b) MLP-Ar-5450 BMB; i) MLP-Ar-5894 BMB. 

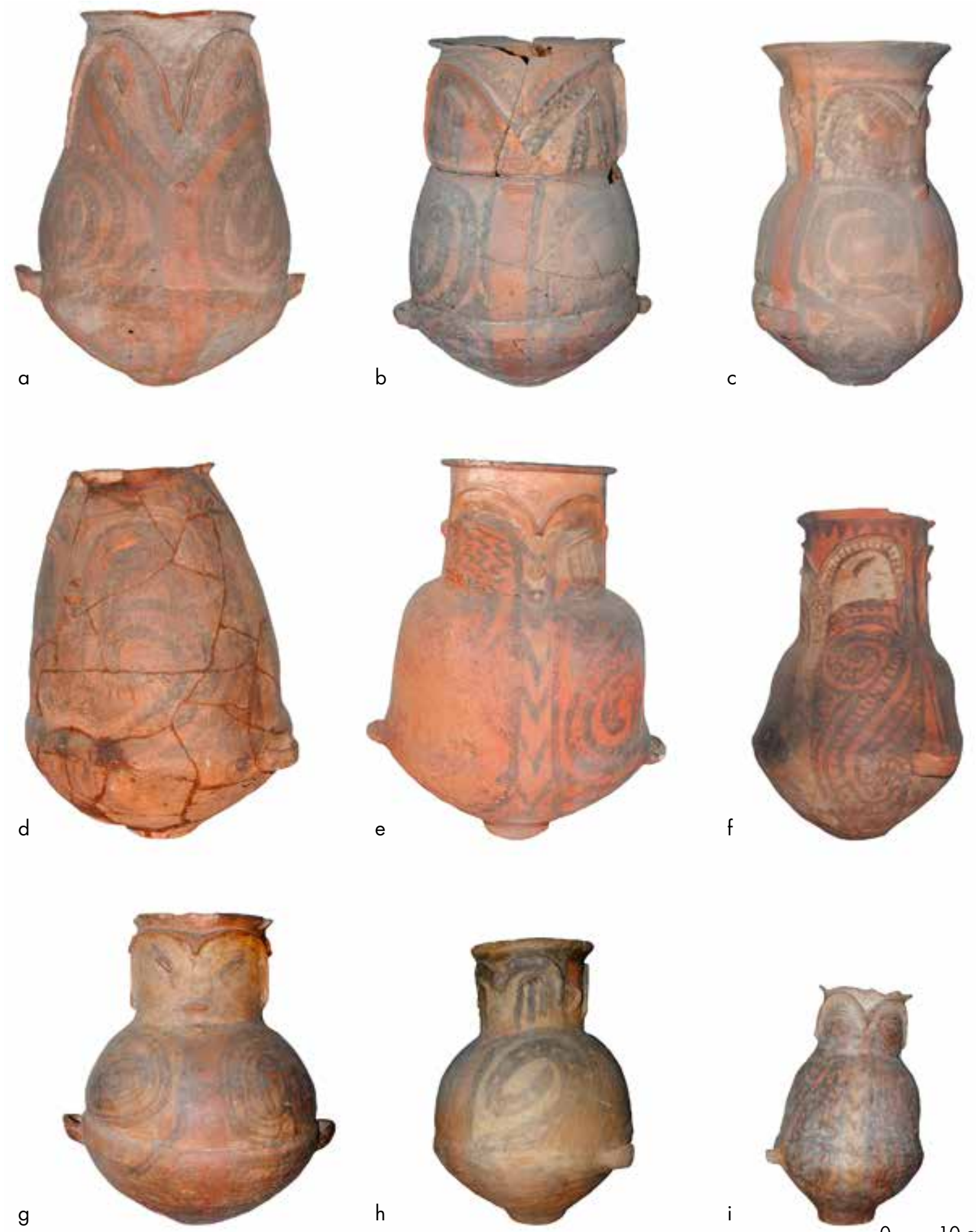

h
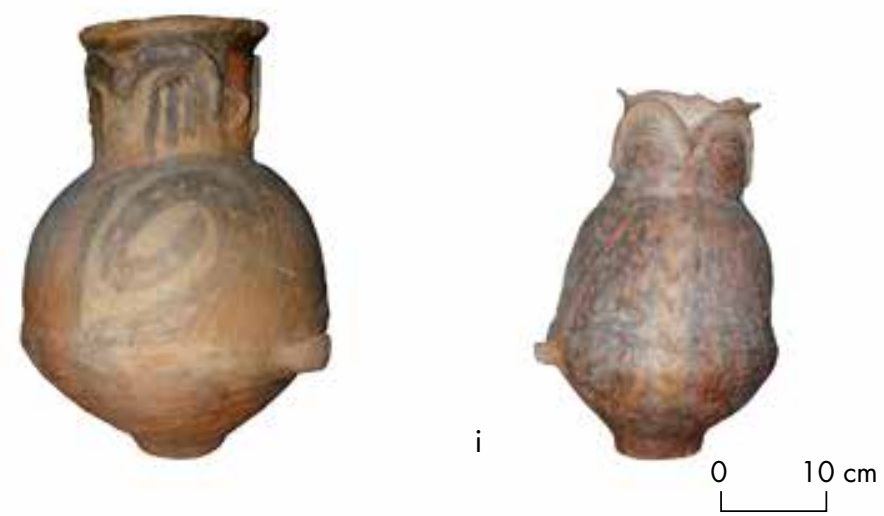

Figura 9. Ejemplos de tinajas antropomorfas con patrón de diseño Lorohuasi: a) MEJBA 44-2041; b) MLP-Ar-5019 BMB; c) MLP-Ar-5448 BMB; d) MEJBA 44-2043; e) MEJBA 12.372; f) MEJBA Z-8467; g) MEJBA 12.388; h) MLP-Ar-4950 SLQ; i) MLP-Ar-2608 FPM.

Figure 9. Examples of anthropomorphic jars with the Lorohuasi design pattern: a) MEJBA 44-2041; b) MLP-Ar-5019 BMB; c) MLP-Ar-5448 BMB; d) MEJBA 44-2043; e) MEJBA 12.372; f) MEJBA Z-8467; g) MEJBA 12.388; b) MLP-Ar-4950 SLO; i) MLP-Ar-2608 FPM. 


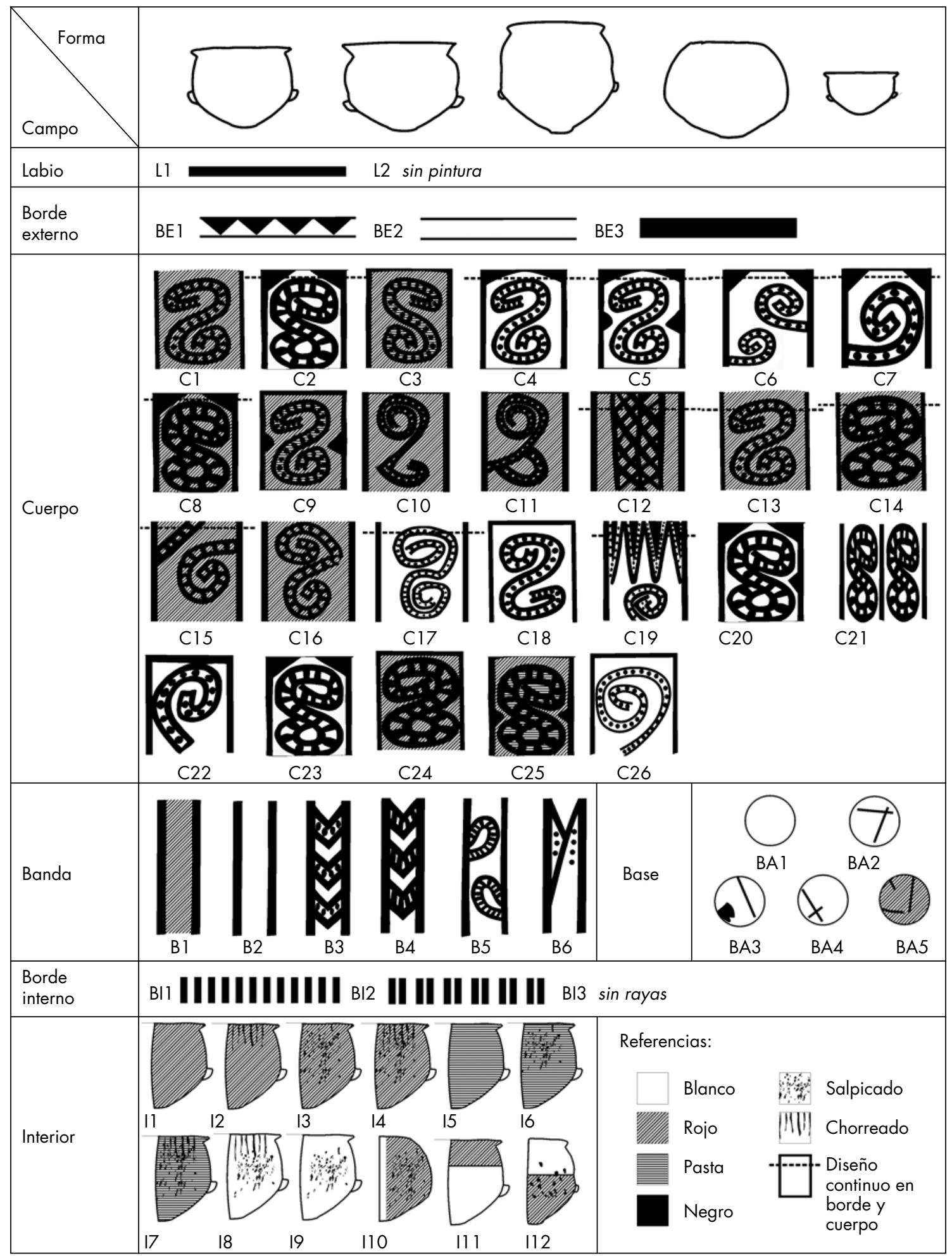

Figura 10. Composiciones de diseño en ollas con patrón Lorohuasi. Figure 10. Composition of designs on pots with the Lorohuasi pattern. 


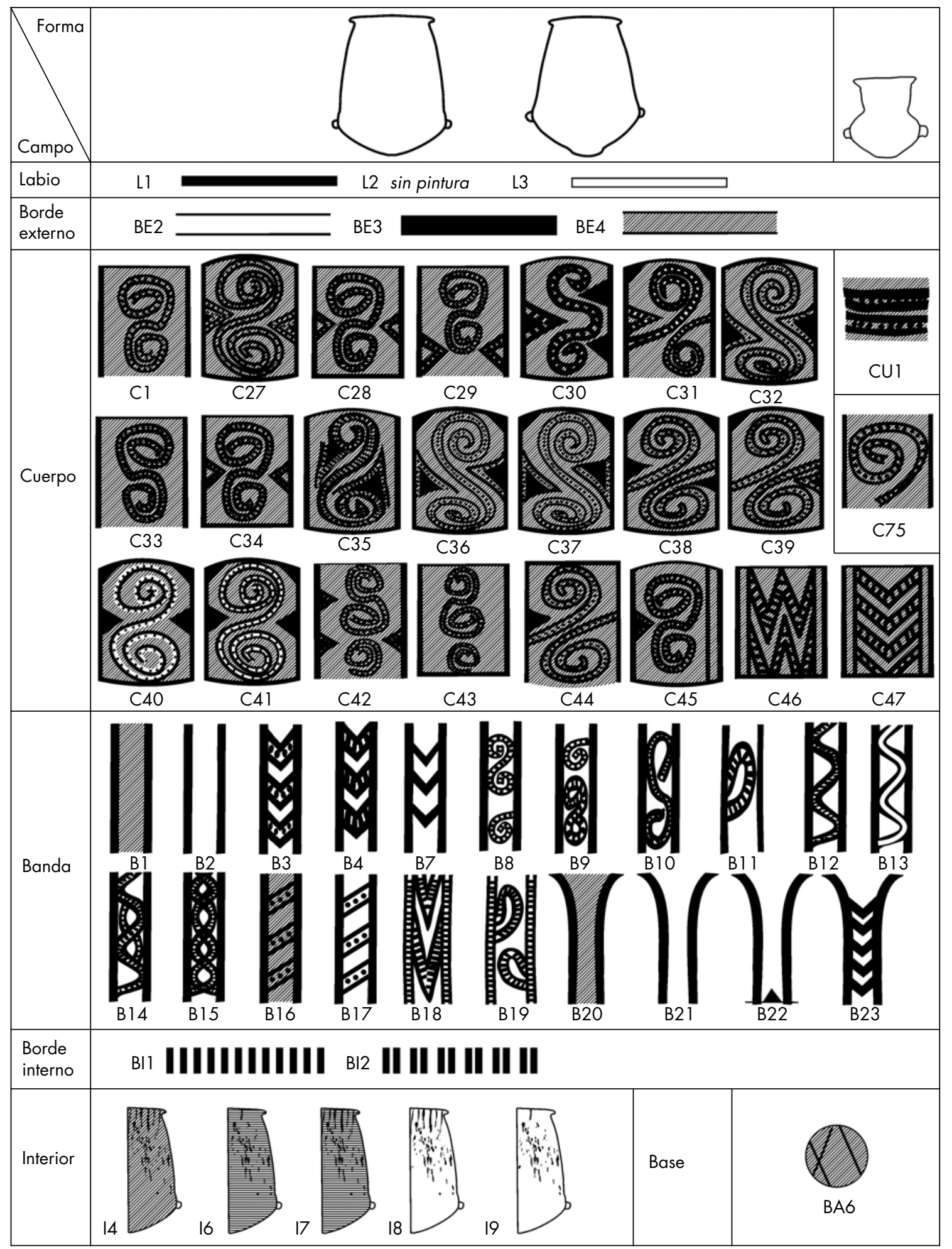

Figura 11. Composiciones de diseño en tinajas con patrón Lorohuasi. Figure 11. Composition of designs on jars with the Lorohuasi pattern. 


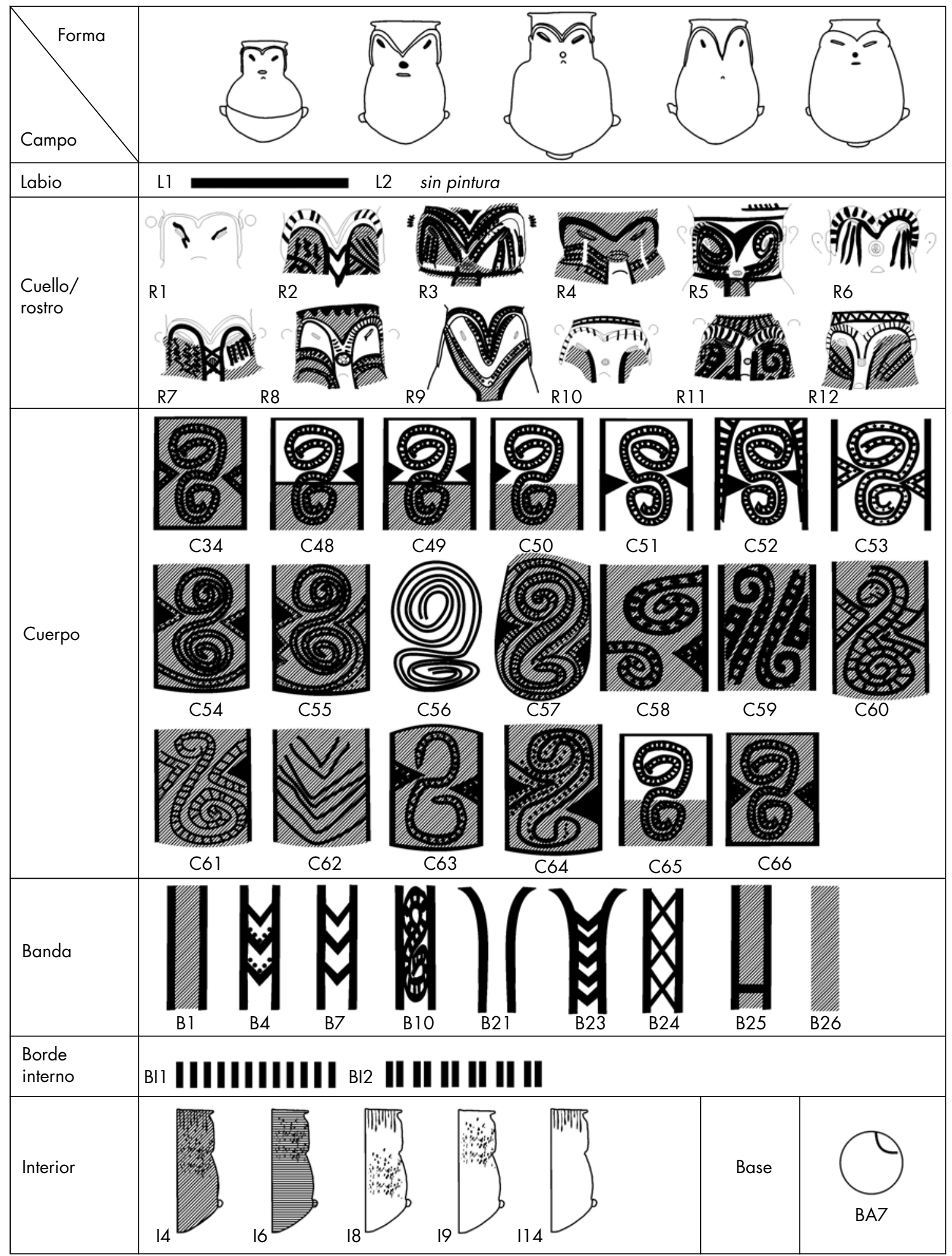

Figura 12. Composiciones de diseño en tinajas antropomorfas con patrón Lorohuasi. Figure 12. Composition of designs on anthropomorphic jars with the Lorohuasi pattern. 


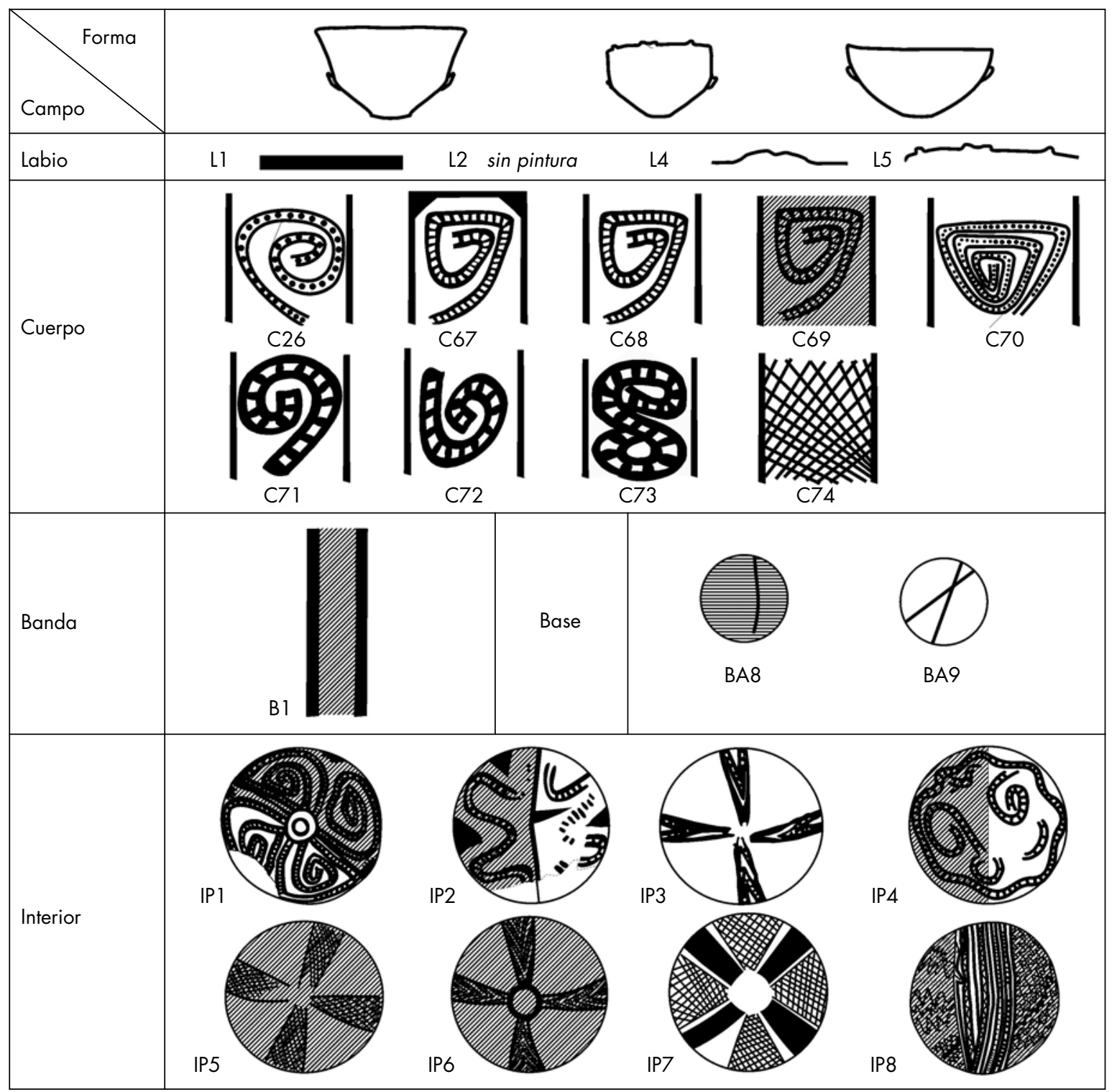

Figura 13. Composiciones de diseño en pucos con patrón Lorohuasi. Figure 13. Composition of designs on bowls with the Lorohuasi pattern.

los diseños que portan. La "S" es reemplazada por una "media S", es decir, un segmento que comprende la mitad superior del motivo, adecuándolo a un espacio menor y más bajo.

La superficie interna adquiere complejidad; las salpicaduras son reemplazadas por diseños complejos de líneas dobles con una estructura conformada por uno a cuatro campos. Aparece en los pucos el modelado, pero esta vez las aplicaciones se disponen sobre el labio de la vasija y configuran cuatro extremidades y dos cabezas opuestas o bien cuatro apéndices indeterminados. Se observaron dos pucos con modelados sobre el labio
(25\% de los pucos). Un proceso asociativo semejante al experimentado en el caso de las tinajas y la abstracción antropomorfa se produce con los pucos y la abstracción zoomorfa, si bien en este último caso los ejemplares modelados son mucho más escasos y la relación puede llegar a perder sustento.

Aun manteniéndose la cuatripartición y el tema de la serpiente como un elemento central y común a todas las formas de vasijas contempladas, el análisis nos permite detectar otro plano de significaciones vinculado al recurso plástico del modelado y a un proceso metonímico que polariza el conjunto, por un lado el grupo de las 
tinajas y lo antropomorfo, por el otro, el de los pucos y lo zoomorfo. En este plano de significaciones el tema y la forma se condicionan mutuamente.

En este posible escenario, ¿qué ocurre con este plano de sentidos en el conjunto de las ollas Lorohuasi? En ellas no hallamos ningún ejemplar modelado; sin embargo, pensamos que algunos atributos de forma, proporciones, colores y diseño llevan a la percepción de mayor semejanza con las tinajas y la abstracción antropomorfa. Estos son el diseño de la "S" completa en el exterior, el chorreado en el interior y la forma restringida con borde evertido rayado, semejante a la morfología del cuerpo en las tinajas con modelado. Con relación al juego de colores es interesante que las tinajas con modelado antropomorfo y las ollas Lorohuasi admitan bandas y campos rojos o blancos, un dato que acerca a ambos conjuntos en cuanto a las posibilidades de combinación y los diferencia de las tinajas sin modelado y los pucos.

Pero un elemento externo a las vasijas -las pautas de uso en los contextos funerarios- aporta "ambigüedad". En los entierros de infantes las tinajas ofician de contenedoras y los pucos se colocan de modo invertido como tapa. ${ }^{14}$ Las ollas Lorohuasi, en cambio, pueden ser tanto contenedor como tapa. La vinculación entre la morfología y el simbolismo zoomorfo o antropomorfo ¿tiene alguna relevancia a la hora de determinar el uso funerario de estas piezas como contenedores o tapas? ¿Es factible que su versatilidad funcional se relacione con la posibilidad de evocar diferentes referentes según su situación de uso o simplemente se relacione con una morfología y proporciones adecuadas para ambos fines más allá del simbolismo que portan?

\section{PRECISIONES ESPACIALES Y TEMPORALES}

De acuerdo con la muestra considerada vemos que los hallazgos de ollas de morfología y patrón de diseño Lorohuasi se circunscriben a la zona centro sur de Yocavil. Por su parte, la distribución en el ámbito regional de otras morfologías que portan el patrón de diseño, incluyendo aquellas con figuración modelada, es más generalizada e incluye sitios en el valle del Cajón y un caso aislado en Hualfín (fig. 14).

A partir de una búsqueda exhaustiva reunimos 17 contextos funerarios que contienen vasijas con patrón de diseño Lorohuasi; con excepción de dos casos de rescate recientes, la información procede de las libretas de campo de Weiser (1921) y Weiser y Wolters (19221924) de las expediciones III, IV y VI. Los contextos se encontraron en su mayoría en áreas funerarias del valle de Yocavil y en menor proporción en el valle del Cajón y consisten en entierros de subadultos en urna con edades variables hasta los seis años. En todos los casos el grado de certeza en la asociación entre la cerámica es de Grado I (Altamente Probable), sensu Palamarczuk (2011). Se identificaron asociaciones de cerámica con patrón Lorohuasi solamente con estilos correspondientes a la estética San José. La asociación

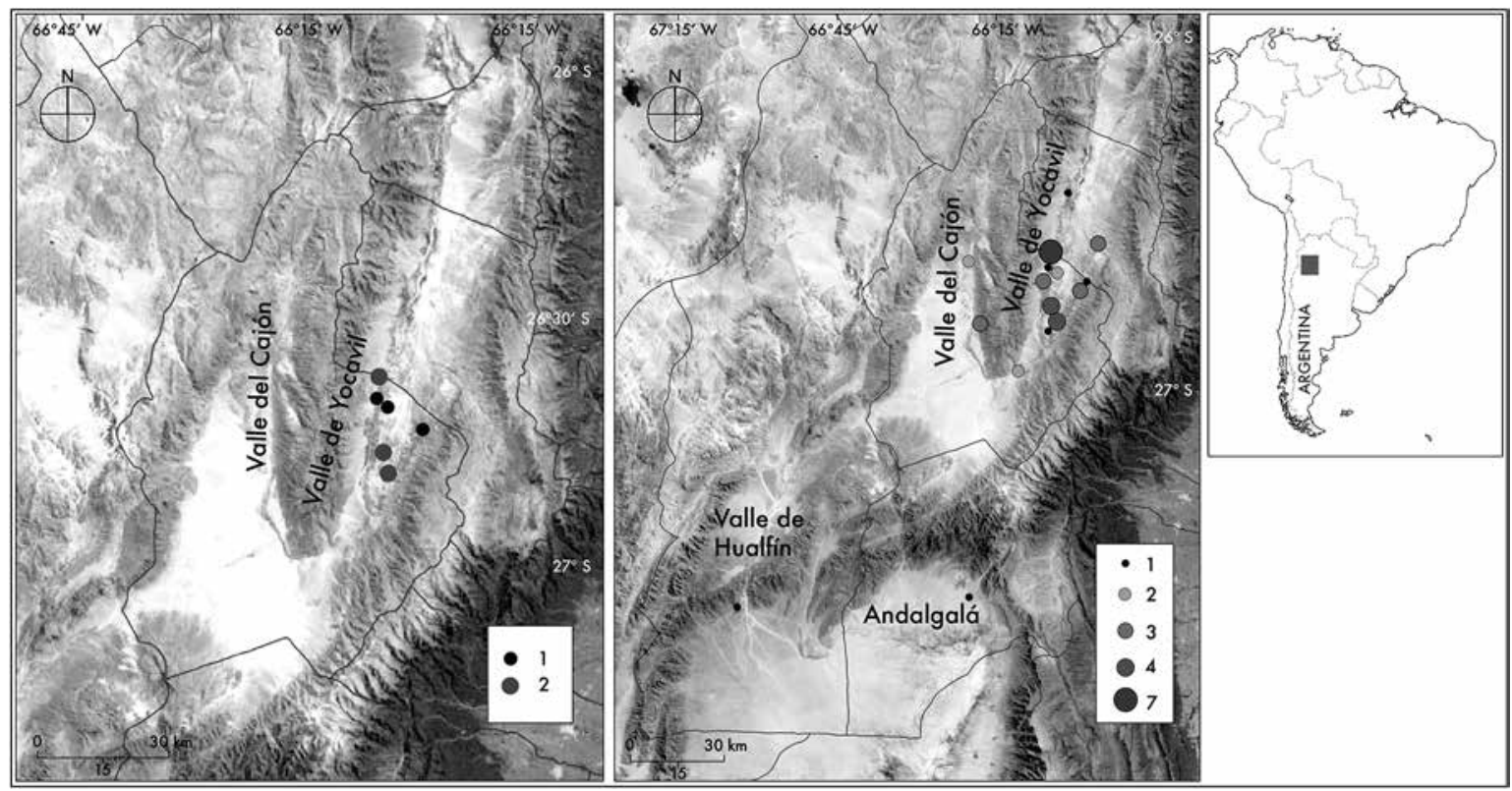

Figura 14. Distribución espacial de la muestra: a) Ollas Lorohuasi; b) otras formas con patrón de diseño Lorohuasi. Figure 14. Spatial distribution of the sample: a) Lorohuasi pots; b) other forms with the Lorohuasi design pattern. 
más frecuente se da con ollas o pucos con patrón de diseño Lorohuasi funcionando como tapa de urnas con patrones de diseño denominados Entre Ríos o Negativos y Sapitos (Palamarczuk et al. 2014) (Tabla 1). Aparte de estos contextos funerarios se reconstruyeron otros con vasijas de forma afín a las ollas Lorohuasi y diferente patrón de diseño, hallando similares tendencias en usos y asociaciones (Tabla 2).

Contamos con cinco fechados radiocarbónicos de cuatro contextos funerarios con niveles de asociación muestra-evento y fechado-cerámica de Tipo I (Completamente cierta y Altamente Probable) (Greco

Tabla 1. Contextos de hallazgo conocidos de vasijas con patrón de diseño Lorohuasi y asociaciones contextuales. Table 1. Known find-contexts of pots with the Lorohuasi design pattern, with contextual associations.

\begin{tabular}{|c|c|c|c|c|c|c|c|}
\hline $\mathrm{N}^{\circ}$ & $\begin{array}{c}\mathrm{N}^{\circ} \\
\text { catálogo }\end{array}$ & Forma & Procedencia & Tipo de entierro & Función & Asociaciones & $\begin{array}{c}\text { Fuente } \\
\text { bibliográfica }\end{array}$ \\
\hline 1 & $\begin{array}{l}\text { MLP-Ar- } \\
6293 \text { BMB }\end{array}$ & Olla & $\begin{array}{l}\text { Las Mojarras "en } \\
\text { una finca á pie del } \\
\text { cerro pintado hacia } \\
\text { el norte". }\end{array}$ & $\begin{array}{l}\text { Niño de } 4-5 \text { años en } \\
\text { una olla ordinaria } \\
\text { tapada con olla } \\
\text { patrón Lorohuasi. }\end{array}$ & Tapa & $\begin{array}{l}\text { Olla ordinaria, } \\
\text { no observada. }\end{array}$ & $\begin{array}{c}\text { Weiser- } \\
\text { Wolters VI } \\
\text { Expedición. }\end{array}$ \\
\hline 2 & $\begin{array}{l}\text { MLP-Ar- } \\
5828 \text { BMB }\end{array}$ & Olla & $\begin{array}{c}\text { Entre Ríos } \\
\text { "Quebrada Entre } \\
\text { Ríos (Chiquimil) } \\
\text { la parte la loma } \\
\text { mesada. Cementerio } \\
\text { N }^{\circ} \text { II". }\end{array}$ & $\begin{array}{c}\text { Niño de } 4-5 \text { años en } \\
\text { tinaja San José patrón } \\
\text { negativos y sapitos } \\
\text { tapada con olla } \\
\text { patrón Lorohuasi. }\end{array}$ & Tapa & $\begin{array}{l}\text { Tinaja patrón } \\
\text { Negativos y } \\
\text { Sapitos MLP-Ar- } \\
5826 \text { BMB. }\end{array}$ & $\begin{array}{c}\text { Weiser- } \\
\text { Wolters VI } \\
\text { Expedición. }\end{array}$ \\
\hline 3 & $\begin{array}{l}\text { MLP-Ar- } \\
6973 \text { BMB }\end{array}$ & Olla & $\begin{array}{l}\text { Lorohuasi "lado } \\
\text { hacia el Sud. } \\
\text { Cementerio No II del } \\
\text { río seco de la loma } \\
\text { redonda". }\end{array}$ & $\begin{array}{l}\text { Niño de 5-6 años en } \\
\text { tinaja San José tapada } \\
\text { con olla patrón } \\
\text { Lorohuasi. }\end{array}$ & Tapa & $\begin{array}{c}\text { Tinaja } \\
\text { morfología } \\
\text { San José, no } \\
\text { observada. }\end{array}$ & $\begin{array}{c}\text { Weiser- } \\
\text { Wolters VI } \\
\text { Expedición. }\end{array}$ \\
\hline 4 & $\begin{array}{l}\text { MLP-Ar- } \\
5962 \text { BMB }\end{array}$ & Olla & $\begin{array}{c}\text { Lorohuasi } \\
\text { "Cementerio río } \\
\text { seco cancino al pie } \\
\text { de la loma redonda } \\
\text { (lado del río hacia el } \\
\text { norte). }\end{array}$ & $\begin{array}{l}\text { Niño de } 4-5 \text { años en } \\
\text { tinaja San José patrón } \\
\text { Entre Ríos tapada con } \\
\text { olla patrón Lorohuasi. }\end{array}$ & Tapa & $\begin{array}{l}\text { Tinaja patrón } \\
\text { Entre Ríos MLP- } \\
\text { Ar-5901 BMB. }\end{array}$ & $\begin{array}{c}\text { Weiser- } \\
\text { Wolters VI } \\
\text { Expedición. }\end{array}$ \\
\hline 22 & $\mathrm{~S} / \mathrm{N}$ & Olla & $\begin{array}{l}\text { Entre Ríos "Camino } \\
\text { de la quebrada". }\end{array}$ & $\begin{array}{l}\text { Infante de alrededor } \\
\text { de un año en una } \\
\text { olla patrón Lorohuasi } \\
\text { tapada con un } \\
\text { fragmento de tinaja } \\
\text { San José patrón Entre } \\
\text { Ríos. }\end{array}$ & Contenedor & $\begin{array}{l}\text { Gran fragmento } \\
\text { de tinaja San } \\
\text { José patrón } \\
\text { Entre Ríos. }\end{array}$ & $\begin{array}{c}\text { Álvarez } \\
\text { Larrain et al. } \\
\text { (2012). }\end{array}$ \\
\hline 24 & $\begin{array}{l}\text { MLP-Ar- } \\
5194 \text { BMB }\end{array}$ & Olla & $\begin{array}{l}\text { Famabalasto } \\
\text { "Cementerio a } \\
\text { pie del cerro } \\
\text { (quebradita)". }\end{array}$ & $\begin{array}{l}\text { Niño de } 4-5 \text { años en } \\
\text { olla patrón Lorohuasi } \\
\text { tapada con puco. }\end{array}$ & Contenedor & $\begin{array}{c}\text { Puco } \\
\text { indeterminado, } \\
\text { no observado. }\end{array}$ & $\begin{array}{c}\text { Weiser- } \\
\text { Wolters IV } \\
\text { Expedición. }\end{array}$ \\
\hline 34 & $\begin{array}{l}\text { MLP-Ar- } \\
5881 \text { BMB }\end{array}$ & Tinaja & $\begin{array}{c}\text { Lorohuasi } \\
\text { "Cementerio río seco } \\
\text { cancino al pie de } \\
\text { la loma redonda" } \\
\text { (lado del río hacia el } \\
\text { norte). }\end{array}$ & $\begin{array}{c}\text { Niño de } 4-5 \text { años en } \\
\text { tinaja San José patrón } \\
\text { Lorohuasi tapada con } \\
\text { puco. }\end{array}$ & Contenedor & $\begin{array}{c}\text { Puco } \\
\text { indeterminado, } \\
\text { no observado } \\
\text { MLP-Ar-5882 } \\
\text { BMB. }\end{array}$ & $\begin{array}{c}\text { Weiser- } \\
\text { Wolters VI } \\
\text { Expedición. }\end{array}$ \\
\hline 35 & $\begin{array}{l}\text { MLP-Ar- } \\
5885 \text { BMB }\end{array}$ & Tinaja & $\begin{array}{c}\text { Lorohuasi } \\
\text { "Cementerio río seco } \\
\text { cancino al pie de } \\
\text { la loma redonda" } \\
\text { (lado del río hacia el } \\
\text { norte). }\end{array}$ & $\begin{array}{c}\text { Niño de } 4-5 \text { años en } \\
\text { tinaja San José patrón } \\
\text { Lorohuasi tapada con } \\
\text { puco patrón Shiquimil } \\
\text { tricolor. }\end{array}$ & Contenedor & $\begin{array}{l}\text { Puco patrón } \\
\text { Shiquimil } \\
\text { tricolor MLP-Ar- } \\
5880 \text { BMB. }\end{array}$ & $\begin{array}{c}\text { Weiser- } \\
\text { Wolters VI } \\
\text { Expedición. }\end{array}$ \\
\hline
\end{tabular}


Tabla 1 (continuación).

\begin{tabular}{|c|c|c|c|c|c|c|c|}
\hline $\mathrm{N}^{\circ}$ & $\begin{array}{c}\mathrm{N}^{\circ} \\
\text { catálogo }\end{array}$ & Forma & Procedencia & Tipo de entierro & Función & Asociaciones & $\begin{array}{c}\text { Fuente } \\
\text { bibliográfica }\end{array}$ \\
\hline 47 & $\begin{array}{l}\text { MLP-Ar- } \\
5019 \text { BMB }\end{array}$ & $\begin{array}{l}\text { Tinaja } \\
\text { antrop. }\end{array}$ & $\begin{array}{c}\text { Caspinchango } \\
\text { "Cementerio bajo de } \\
\text { la quebrada corral a } \\
\text { la orilla derecha del } \\
\text { arroyo potrero del } \\
\text { ciénago". }\end{array}$ & $\begin{array}{l}\text { Neonato en tinaja } \\
\text { Peñas Azules Tricolor } \\
\text { sensu Arena (1975) } \\
\text { con diseños patrón } \\
\text { Lorohuasi tapada } \\
\text { con puco. }\end{array}$ & Contenedor & $\begin{array}{c}\text { Puco } \\
\text { indeterminado, } \\
\text { no observado. }\end{array}$ & $\begin{array}{l}\text { Weiser III } \\
\text { Expedición. }\end{array}$ \\
\hline 48 & $\begin{array}{l}\text { MLP-Ar- } \\
5448 \text { BMB }\end{array}$ & $\begin{array}{l}\text { Tinaja } \\
\text { antrop. }\end{array}$ & $\begin{array}{c}\text { Peñas Azules } \\
\text { "Campo del Fraile". }\end{array}$ & $\begin{array}{l}\text { Niño de 2-3 años en } \\
\text { tinaja Peñas Azules } \\
\text { Tricolor sensu Arena } \\
\text { (1975) con diseños } \\
\text { patrón Lorohuasi } \\
\text { tapada con puco } \\
\text { patrón Shiquimil } \\
\text { tricolor. }\end{array}$ & Contenedor & $\begin{array}{l}\text { Puco patrón } \\
\text { Shiquimil } \\
\text { tricolor MLP-Ar- } \\
5449 \text { BMB. }\end{array}$ & $\begin{array}{l}\text { Weiser- } \\
\text { Wolters IV } \\
\text { Expedición. }\end{array}$ \\
\hline 61 & $\begin{array}{l}\text { BMB-Ar- } \\
5450 \text { BMB }\end{array}$ & Puco & $\begin{array}{c}\text { Peñas Azules } \\
\text { "Campo del Fraile". }\end{array}$ & $\begin{array}{l}\text { Niño de 3-4 años en } \\
\text { tinaja Peñas Azules } \\
\text { Antropomorfo sensu } \\
\text { Arena (1975) tapada } \\
\text { con puco patrón } \\
\text { Lorohuasi con } \\
\text { modelado zoomorfo. }\end{array}$ & Tapa & $\begin{array}{c}\text { Tinaja patrón } \\
\text { Peñas Azules } \\
\text { MLP-Ar-5452 } \\
\text { BMB. }\end{array}$ & $\begin{array}{l}\text { Weiser- } \\
\text { Wolters IV } \\
\text { Expedición. }\end{array}$ \\
\hline 62 & $\begin{array}{l}\text { BMB-Ar- } \\
4992 \text { BMB }\end{array}$ & Puco & $\begin{array}{c}\text { Masao "Cementerio } \\
\text { Maravilla". }\end{array}$ & $\begin{array}{l}\text { Entierro en tinaja San } \\
\text { José patrón Entre } \\
\text { Ríos tapada con puco } \\
\text { patrón Lorohuasi. No } \\
\text { se describe contenido. }\end{array}$ & Tapa & $\begin{array}{l}\text { Tinaja patrón } \\
\text { Entre Ríos MLP- } \\
\text { Ar-5074 BMB. }\end{array}$ & $\begin{array}{c}\text { Weiser III } \\
\text { Expedición. }\end{array}$ \\
\hline 63 & $\begin{array}{l}\text { BMB-Ar- } \\
5894 \text { BMB }\end{array}$ & Рuco & $\begin{array}{c}\text { Entre Ríos } \\
\text { "Quebrada Entre } \\
\text { Ríos (Chiquimil) } \\
\text { la parte la loma } \\
\text { mesada. Cementerio } \\
\text { No II". }\end{array}$ & $\begin{array}{l}\text { Niño de } 1-2 \text { años en } \\
\text { tinaja San José patrón } \\
\text { Negativos y sapitos } \\
\text { tapada con puco } \\
\text { patrón Lorohuasi. } \\
\text { Entierro encistado. }\end{array}$ & Tapa & $\begin{array}{l}\text { Tinaja patrón } \\
\text { Negativos y } \\
\text { Sapitos MLP-Ar- } \\
5841 \text { BMB. }\end{array}$ & $\begin{array}{c}\text { Weiser- } \\
\text { Wolters VI } \\
\text { Expedición. }\end{array}$ \\
\hline 64 & $\begin{array}{l}\text { BMB-Ar- } \\
5872 \text { BMB }\end{array}$ & Puco & $\begin{array}{c}\text { Entre Ríos } \\
\text { "Quebrada Entre } \\
\text { Ríos (Chiquimil) } \\
\text { la parte la loma } \\
\text { mesada. Cementerio } \\
\text { No III". }\end{array}$ & $\begin{array}{c}\text { Niño de } 3-4 \text { años en } \\
\text { olla ordinaria tapada } \\
\text { con puco patrón } \\
\text { Lorohuasi. }\end{array}$ & Tapa & $\begin{array}{c}\text { Olla ordinaria, } \\
\text { no observada } \\
\text { MLP-Ar-8393 } \\
\text { BMB. }\end{array}$ & $\begin{array}{c}\text { Weiser- } \\
\text { Wolters VI } \\
\text { Expedición. }\end{array}$ \\
\hline
\end{tabular}

2012) con cerámica San José en el valle de Yocavil; dos de ellos están relacionados con vasijas de patrón Lorohuasi. El entierro de Entre Ríos ya mencionado fue datado en 654 43 AP (AA87354), 1293-1408 cal DC (dos sigma - curva de calibración ShCal04, McCormac et al. 2004). En Rincón Chico, en el área funeraria RCh25, el infante en tinaja patrón Lorohuasi y puco tapa Shiquimil

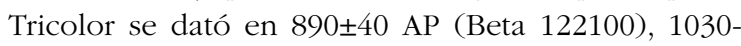
1220 cal DC (dos sigma). Los tres fechados restantes corresponden a infantes enterrados en vasijas y pucos clasificados como variantes Shiquimil. Uno de los entierros, encontrado al este de la ciudad de Santa María,

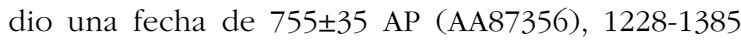

cal DC (dos sigma). El otro, con dos individuos en el interior de la urna, aportó sendos fechados de $863 \pm 43$ AP (AA87355), 1054-1283 cal DC (dos sigma) y 885 \pm 36 AP (AA87360), 1053-1272 cal DC (dos sigma) (Álvarez Larrain et al. 2012) (Tabla 3).

Las calibraciones de estos cinco fechados indican probabilidades que se extienden a lo largo de los primeros cuatro siglos del segundo milenio; resultados que son coherentes con el planteo de que las variantes cerámicas asociadas se produjeron en la primera mitad del Período Tardío. La evaluación preliminar de la temporalidad de los estilos San José realizada por Greco (2012) resulta valiosa, ya que establece una tendencia cronológica 
Tabla 2. Contextos de hallazgo y asociaciones contextuales de vasijas con forma afín a las ollas Lorohuasi (sensu Perrotta \& Podestá 1975) y diferente patrón de diseño.

Table 2. Find-contexts and contextual associations of vessels morphologically similar to the Lorohuasi pots (sensu Perrotta \& Podestá 1975), and with a different design pattern.

\begin{tabular}{|c|c|c|c|c|c|c|}
\hline $\mathrm{N}^{\circ}$ catálogo & Forma & Procedencia & Tipo de entierro & Función & Asociaciones & $\begin{array}{c}\text { Fuente } \\
\text { bibliográfica }\end{array}$ \\
\hline $\begin{array}{c}\text { MLP-Ar-6026 } \\
\text { BMB }\end{array}$ & Olla & $\begin{array}{l}\text { Lorohuasi "lado } \\
\text { hacia el Sud. } \\
\text { Cementerio N II } \\
\text { del río seco de la } \\
\text { loma redonda". }\end{array}$ & $\begin{array}{l}\text { Niño de 5-6 años } \\
\text { en tinaja San José } \\
\text { tapada con olla. }\end{array}$ & Tapa & $\begin{array}{c}\text { Tinaja morfología } \\
\text { San José, no } \\
\text { observada. }\end{array}$ & $\begin{array}{l}\text { Weiser-Wolters VI } \\
\text { Expedición. }\end{array}$ \\
\hline $\begin{array}{c}\text { MLP-Ar-5829 } \\
\text { BMB }\end{array}$ & Olla & $\begin{array}{c}\text { Entre Ríos } \\
\text { "Quebrada Entre } \\
\text { Ríos (Chiquimil) } \\
\text { la parte la } \\
\text { loma mesada. } \\
\text { Cementerio N II". }\end{array}$ & $\begin{array}{l}\text { Entierro en olla } \\
\text { tapada con puco. } \\
\text { No se describe } \\
\text { contenido. }\end{array}$ & Contenedor & $\begin{array}{c}\text { Puco afín a Loma } \\
\text { Rica y Shiquimil } \\
\text { MLP-Ar- } 5744 \\
\text { BMB. }\end{array}$ & $\begin{array}{l}\text { Weiser-Wolters VI } \\
\text { Expedición. }\end{array}$ \\
\hline $\begin{array}{c}\text { MLP-Ar-5861 } \\
\text { BMB }\end{array}$ & Olla & $\begin{array}{c}\text { Entre Ríos } \\
\text { "Quebrada Entre } \\
\text { Ríos (Chiquimil) } \\
\text { la parte la } \\
\text { loma mesada. } \\
\text { Cementerio N II". }\end{array}$ & $\begin{array}{l}\text { Niño de } 1-2 \text { años } \\
\text { en olla tapada con } \\
\text { puco Loma Rica. }\end{array}$ & Contenedor & $\begin{array}{c}\text { Puco Loma Rica } \\
\text { MLP-Ar-5874 } \\
\text { BMB. }\end{array}$ & $\begin{array}{l}\text { Weiser-Wolters VI } \\
\text { Expedición. }\end{array}$ \\
\hline $\begin{array}{c}\text { MLP-Ar-5896 } \\
\text { BMB }\end{array}$ & Olla & $\begin{array}{c}\text { Lorohuasi } \\
\text { "Cementerio río } \\
\text { seco cancino al pie } \\
\text { de la loma redonda } \\
\text { (lado del río hacia } \\
\text { el norte). }\end{array}$ & $\begin{array}{l}\text { Niño de } 4-5 \text { años } \\
\text { en tinaja San José } \\
\text { tapada con olla. }\end{array}$ & Tapa & $\begin{array}{c}\text { Tinaja morfología } \\
\text { San José, no } \\
\text { observada. }\end{array}$ & $\begin{array}{l}\text { Weiser-Wolters VI } \\
\text { Expedición. }\end{array}$ \\
\hline
\end{tabular}

Tabla 3. Fechados radiocarbónicos por AMS con cerámica San José en el valle de Yocavil. Curva de calibración ShCal04 (McCormac et al. 2004).

Table 3. AMS radiocarbon datings of San José pottery from the Yocavil valley. ShCal04 calibration curve (McCormac et al. 2004).

\begin{tabular}{|c|c|c|c|}
\hline Lugar de hallazgo & Fechado & Calibración & Alfarería \\
\hline Entre Ríos & $654 \pm 43$ AP (AA87354) & $\begin{array}{l}1293-1408 \text { cal DC } \\
( \pm 2 \text { sigma })\end{array}$ & $\begin{array}{c}\text { Contenedor, olla patrón Lorohuasi. } \\
\text { Tapa, fragmento de tinaja patrón } \\
\text { Entre Ríos. }\end{array}$ \\
\hline Rincón Chico 25 & $\begin{array}{c}890 \pm 40 \mathrm{AP} \\
(\text { Beta } 122100)\end{array}$ & $\begin{array}{l}1030-1220 \mathrm{cal} \mathrm{DC} \\
( \pm 2 \text { sigma })\end{array}$ & $\begin{array}{l}\text { Contenedor, tinaja patrón Lorohuasi. } \\
\text { Tapa, puco Shiquimil tricolor. }\end{array}$ \\
\hline Santa María & $755 \pm 35$ AP (AA87356) & $\begin{array}{l}1228-1385 \text { cal DC } \\
\quad( \pm 2 \text { sigma })\end{array}$ & $\begin{array}{l}\text { Contenedor, tinaja Shiquimil tricolor. } \\
\text { Tapa, puco Shiquimil tricolor. }\end{array}$ \\
\hline Medanitos & $\begin{array}{l}863 \pm 43 \text { AP (AA87355) } \\
885 \pm 36 \text { AP (AA87360) }\end{array}$ & $\begin{array}{l}1054-1283 \mathrm{cal} D C \\
\quad( \pm 2 \text { sigma }) \\
1053-1272 \mathrm{cal} \mathrm{DC} \\
\quad( \pm 2 \text { sigma })\end{array}$ & $\begin{array}{l}\text { Contenedor, tinaja Shiquimil } \\
\text { dameros. } \\
\text { Tapa, puco Shiquimil dameros. }\end{array}$ \\
\hline
\end{tabular}

diferente a la observada para otros estilos tardíos de Yocavil, como Santa María, Famabalasto Negro Grabado, Inka y Caspinchango. En la comparación efectuada, para el conjunto San José se observa que el rango cronológico con mayor densidad de probabilidades -correspondiente a los fechados calibrados con un sigma- se sitúa entre fines del siglo XII y comienzos del siglo XIV, mientras que para el caso Santa María, si bien existe solapamiento, las áreas de máxima probabilidad indican épocas más tardías. Por último, los fechados vinculados con el patrón 
Lorohuasi se ubican en ambos extremos del rango temporal establecido mediante radiocarbono para San José.

En principio, esto nos permite pensar en la continuidad en el uso de este patrón de diseño en un marco de tiempo amplio. Sin embargo, debido a que la muestra de estudio disponible es muy pequeña, para avanzar en esta línea de investigación será necesario obtener un conjunto de dataciones más abundante.

\section{PERDURACIONES Y CONTINUIDADES}

El radiocarbono y las asociaciones estilísticas nos permitieron colocar en un rango temporal al conjunto observado. El análisis de ciertos rasgos del diseño posibilita la indagación de continuidades e innovaciones en una perspectiva temporal amplia. En los campos del cuerpo el diseño de la "S" o media "S" vertical alude al tema de la serpiente. La interpretación del simbolismo en las representaciones visuales calchaquíes fue un tema importante para los investigadores pioneros de la arqueología y el folclore regional. De acuerdo con Ambrosetti (1896), el simbolismo de la serpiente se vincula con dos significaciones potentes y mutuamente relacionadas, la serpiente figurada en las vasijas funerarias como buaca guardiana o protectora de los muertos y la serpiente rayo ligada a fenómenos meteorológicos como el rayo, el trueno, las precipitaciones y, por medio de ellas, el agua imprescindible para la fertilidad. Quiroga (1899), en esa misma línea de reflexiones, destaca la asociación entre el simbolismo de la fertilidad y la figura de la serpiente rayo de carácter fálico que fertiliza la tierra, femenina.

En la cosmovisión de los pueblos tardíos en la región el simbolismo de la serpiente destaca por la multiplicidad y abundancia de los signos visuales que lo evocan en variados soportes, como la alfarería, los objetos de bronce, de hueso, de madera, los textiles y el arte rupestre. En nuestro caso, la ubicación de las serpientes en el cuerpo de las vasijas antropomorfas, en un espacio que corresponde a la vestimenta, permite trazar relaciones entre la tecnología alfarera y los textiles, en los que esta clase de figuración pudo ser también frecuente e, inclusive, pudo estar ligada al atuendo de ciertas personalidades o personajes mitológicos, representados en las vasijas.

La serpiente es un tema primordial que permite establecer relaciones y continuidades entre el mundo del simbolismo San José y Santa María. Afinidades que cobran gran claridad al centrar la mirada en las piezas con representación antropomorfa modelada, que evidencian, más allá de las claras diferencias, una notable unidad de sentido. Arena (1975) planteó a modo de hipótesis que esta clase de vasijas antropomorfas -en especial aquellas a las que llamó Peñas Azules Tricolor y que ilustramos en la fila superior de la figura 9-, podían considerarse de "transición" entre San José y Santa María. ${ }^{15}$ Se trata de una idea sugerente. Mientras que el diseño pintado registra al universo San José, el diseño modelado antropomorfo, las proporciones y la segmentación del cuerpo muestran importantes semejanzas con Santa María. Pero más allá de las diferencias en el modo de representación, el carácter dual del personaje antropomorfo es un elemento de estrecha correspondencia. ¿Cómo evaluar esta posibilidad? Como vimos, las asociaciones de contextos funerarios conocidos son pocas y comprenden objetos que se inscriben en la estética San José; no hay asociaciones con cerámicas Santa María. Por lo demás, los fechados radiocarbónicos son todavía escasos y aún no se obtuvo ninguno en asociación a esta clase de vasijas antropomorfas. No obstante, de los cinco fechados disponibles los dos que corresponden a los extremos temporales se relacionan a vasijas con patrón Lorohuasi. ¿La representación antropomorfa abstracta antecede a la figuración modelada? No podemos aún afirmarlo, pero sí podemos conjeturar, a partir de los datos radiocarbónicos disponibles, una perduración de la abstracción antropomorfa a lo largo del lapso de producción de los estilos San José.

El análisis del caso Lorohuasi aporta información interesante para considerar una intención de representación antropomorfa en las vasijas San José, que antecede al desarrollo santamariano, y que puede ser útil para reflexionar sobre las hipótesis en torno a la confluencia de factores locales y extralocales en el origen y desarrollo de esa última estética (Tartusi \& Núñez Regueiro 2003).

En este sentido son valiosas las indagaciones de Bugliani (2004) acerca de la representación de la figura humana en vasijas efigie que circularon en épocas previas, durante el Formativo, como bloque temporal amplio, en Yocavil y alrededores. Encuentra particularidades locales en los recursos plásticos, compositivos y expresivos: cuerpo de la vasija que participa como elemento de la representación, postura vertical de la figura, imagen frontal del personaje, modelado del rostro en un cuello, ausencia de combinación entre figura humana y animal, metonimia como recurso expresivo a partir de la selección de solo algunos atributos para la composición de la figura humana. La autora considera a estas manifestaciones como expresión de tendencias acerca de la concepción del mundo en las sociedades pretardías y concluye destacando las afinidades entre la representación antropomorfa en vasijas pretardías y las urnas Santa María del Tardío, evidenciando la perduración de un contenido simbólico, 
el tema antropomorfo, en un tiempo largo que cruza diferentes épocas en el devenir de las sociedades de Yocavil. Su análisis permite rastrear un tema y modos de representación persistentes plasmados en vasijas, en la profunda historia regional y apreciar continuidades y rupturas en épocas posteriores.

Pero queremos destacar que la persistencia del tema antropomorfo adquiere en las manifestaciones tardías un carácter radicalmente nuevo: la figura humana dual. Si bien la figuración antropomorfa modelada es un tema muy afianzado que puede rastrearse dos milenios en el remoto Formativo local, continúa con tintes novedosos en épocas tardías en una singular composición que reconoce dos caras en una misma pieza, las vasijas con rostros dobles, que están presentes de manera minoritaria en el universo San José (el 10\% de la muestra presenta figuración antropomorfa) y que caracterizan a la casi totalidad de las urnas Santa María, instalándose como un tema principal que perduró por varios siglos y que ha sido sujeto a diferentes interpretaciones desde la arqueología (una deidad, representaciones sexuadas, representaciones de las madres de los infantes, del infante contenido en la urna, etc.) (Weber 1981; Nastri 2008; Velandia 2005).

Otro interesante juego de dualidad lo vemos en el contraste mencionado entre pucos zoomorfos y tinajas antropomorfas. Este es un límite que no se traspasa en el universo de alfarerías San José, no hay antropomorfos modelados en pucos, ni zoomorfos modelados en tinajas, parecería haber un campo semántico reservado a los diferentes grupos de formas.

El concepto de dualidad como categoría metafísica de gran nivel de abstracción expresado por medio del arte a partir de oposiciones, desdoblamientos y simetrías resulta un aspecto central de la cosmovisión de los pueblos andinos, relacionado con la organización del mundo natural y social y los momentos de pasaje como la muerte (Ataliva 2000; Llamazares 2011). A los principios duales de la organización del diseño expuestos se suman en nuestro ejemplo otros como la cuatripartición de los campos, la figura de la "S" sinuosa que implica una simetría en el motivo, el contraste de tonos y la oposición de gran contraste entre un "exterior" muy estructurado y equilibrado y un "interior" de diseño dinámico y caótico. Estos principios duales en la producción de las vasijas son en sí mismos aspectos cuyo análisis debemos profundizar.

\section{CONCLUSIONES}

La búsqueda de contextualización de un hallazgo puntual y azaroso derivó en una extraordinaria serie de relaciones entre grupos de vasijas. Pudimos identificar un patrón de diseño que, con variaciones, se manifiesta de modo muy repetitivo. Observamos cómo aquel aparece con un perfil singular en múltiples formas, lo que nos permitió sugerir que el diseño como totalidad se vincula con un proceso de abstracción de figuras humanas y animales en el que cada vasija simboliza a un ser humano, en unos casos, o a un cuadrúpedo en otros, y donde a su vez es medular el símbolo de la serpiente.

En otro trabajo describimos los diferentes patrones de diseño identificados en el universo San José (Palamarczuk et al. 2014), que sintetizamos aquí en la figura 15 considerando las variantes mayoritarias y las relaciones con la estética Santa María. ${ }^{16}$ Integrar el conjunto analizado aquí dentro de una muestra mayor de variantes que componen la estética San José fue otro paso necesario, ya que el sistema comunicacional del cual los modelos observados participan es sumamente complejo y variado. Una perspectiva que otorga peso al contexto impide el circunscribirnos a una única clase de manifestaciones, las que, no obstante, son aisladas como un paso metodológico bajo la premisa de que las elecciones en la forma y el diseño y sus combinaciones no son azarosas, sino que obedecen a fines comunicacionales, integrando sistemas visuales semasiográficos. La síntesis gráfica (fig. 15) permite ver que en San José el modelado antropomorfo aparece de manera insistente y mayoritaria en piezas con el patrón Lorohuasi o con un patrón bipartito con varios puntos de contacto en los diseños. ${ }^{17}$ Hay una selección explícita, limitada y no azarosa de los diseños y composiciones que pueden acompañar a la figura humana en este sistema visual, que refuerza la percepción del antropomorfo en las ollas y tinajas patrón Lorohuasi sin modelado, mediante la figuración del segmento del cuerpo-atuendo de los personajes.

La insistencia en la repetición de patrones como el Lorohuasi en una amplia región que incluye fundamentalmente al centro-sur de Yocavil y el valle del Cajón, con casos aislados en Andalgalá y Hualfín, reafirma la eficacia de los códigos visuales plasmados y compartidos por diferentes comunidades. El patrón de diseño que a simple vista se presenta igual y monótono, con un limitado stock de motivos, es capaz de contener pequeñas diferencias en la composición del diseño en cada campo, o de la simetría entre campos, que hacen de cada vasija una pieza única. Las figuras 10 a 13 revelan la impresionante diversidad de composiciones registradas.

Vemos en la heterogeneidad de la ejecución de cada vasija muchas manos contribuyendo a su producción, con diversas habilidades y materiales a disposición y seguramente siguiendo las enseñanzas de diferentes 


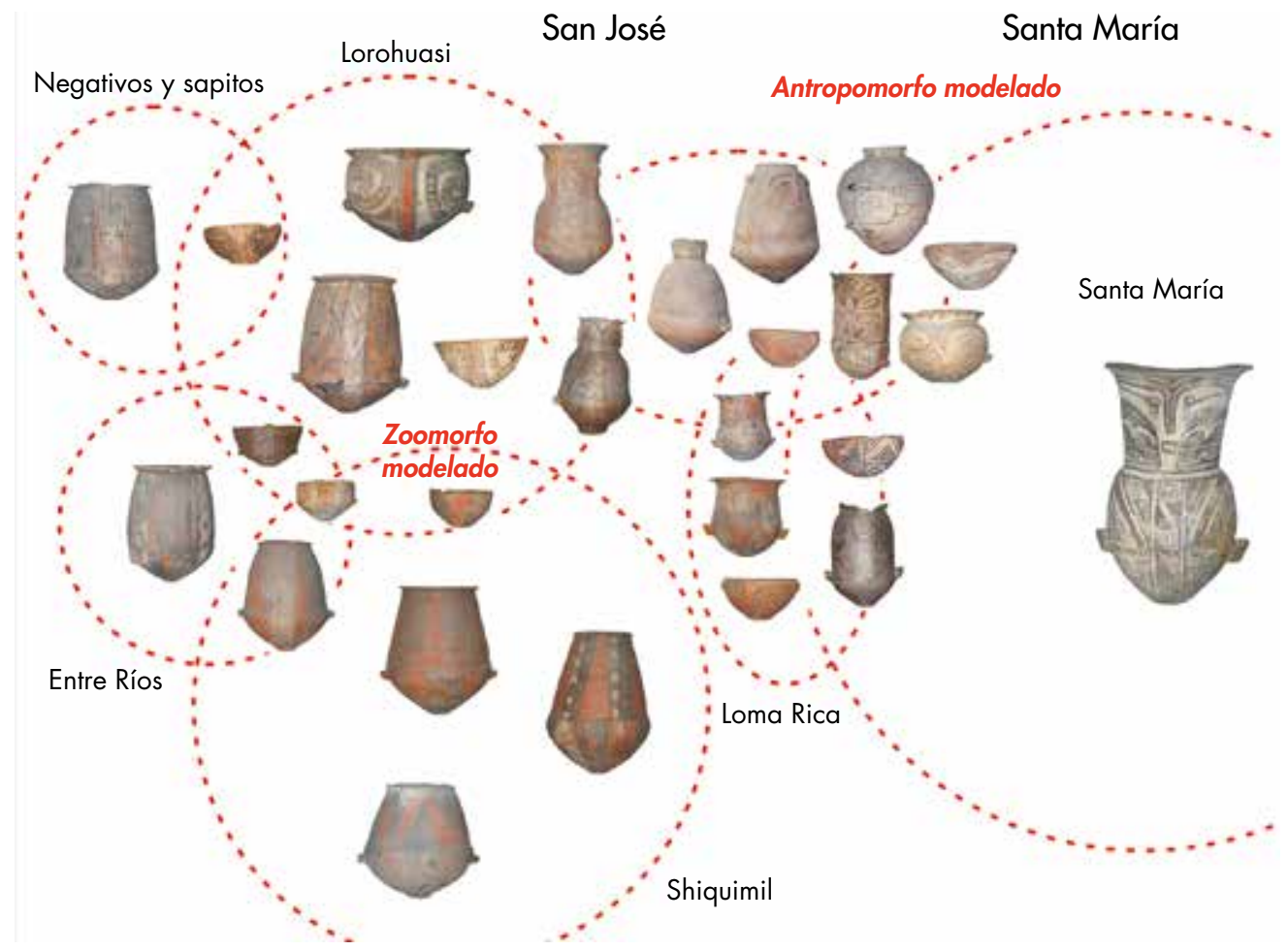

Figura 15. Síntesis de las variantes estilísticas en el universo San José y sus relaciones mutuas a base de rasgos intrínsecos. Figure 15. Summary of stylistic variants in the San José universe, with linkages based on intrinsic features.

maestros, todos aportando rasgos de variación a un conjunto que, si bien posee claros y persistentes gestos y pautas de producción, parece no buscar repeticiones exactas, sino por el contrario, producir pequeñas diferencias dentro de un todo sumamente estructurado. Este dato es muy interesante para reflexionar respecto de las instancias de reproducción de los códigos visuales y el grado de dominio colectivo e individual acerca de los mismos, la capacidad de producir las vasijas y realizar los diseños en ellas, de reproducir y participar del código visual como comunicador y como receptor y en qué medida la introducción de modificaciones leves en la composición de diseños acotados dentro de un patrón pautado responde a necesidades comunicacionales y afecta a los diferentes planos de significados en este sistema visual.

A su vez, y en una escala temporal amplia, la constatación de la perduración de ciertos temas y signos visuales en un tiempo largo lleva a preguntarnos acerca de la medida en la cual los significados asociados pudieron mutar en el espacio y a lo largo del tiempo. También acerca de a qué necesidades sociales pudieron responder la creación y la estabilización de las representaciones que caracterizan a la estética San José y a su posterior superación en la estética Santa María.
La afirmación de la estética San José se produjo en un contexto social de importantes cambios políticos y territoriales vinculados con el desarrollo de la vida en poblados aglomerados -y defensivos- durante el período Tardío en Yocavil, cuyos inicios deben aun indagarse mediante diferentes líneas de evidencia. Pensamos que el estudio del universo de representaciones en la alfarería San José, tarea en la que intentamos avanzar con el trabajo expuesto, pero que desde luego requiere de mayores esfuerzos desde diversos enfoques, contribuirá a dilucidar aspectos de dicho proceso de cambio.

Para avanzar en la línea de estudio aquí expuesta planeamos ampliar el panorama integrando al análisis del sistema de comunicación semasiográfico las múltiples variantes estilísticas identificadas. Asimismo será importante ampliar la muestra de vasijas incluyendo otras colecciones de museos e incorporar el estudio de la variabilidad sobre aspectos tecnológicos de la producción de los estilos.

RECONOCIMIENTOS A Alejandra Reynoso, Marina Marchegiani, Juan Manuel Estévez y Gabriela Amiratti del Museo Etnográfico "Juan B. Ambrosetti". A Rubén Quiroga y Arnaldo Vargas del Museo Arqueológico Provincial "Eric Boman". A Gabriel Alarcón, Jorge Kraideberg, Gustavo Tolosa, Jorgelina Collazo, Ana Igareta y Rodolfo Raffino del Museo de La Plata. A Beatriz Cremonte, Emily Stovel, Frank Salomon, Romina Spano y Myriam Tarragó. A los evaluadores y editores del Boletín. 


\section{च

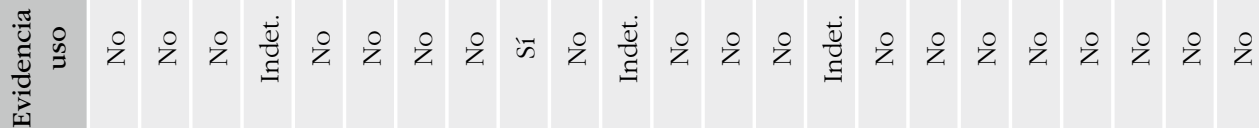

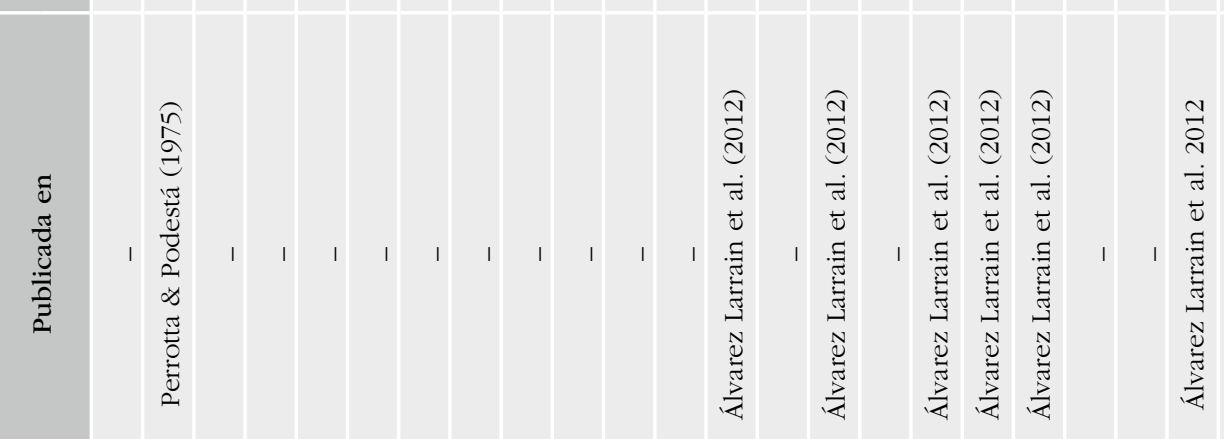

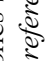

竞

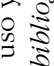

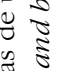

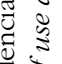

告 8

(1) 


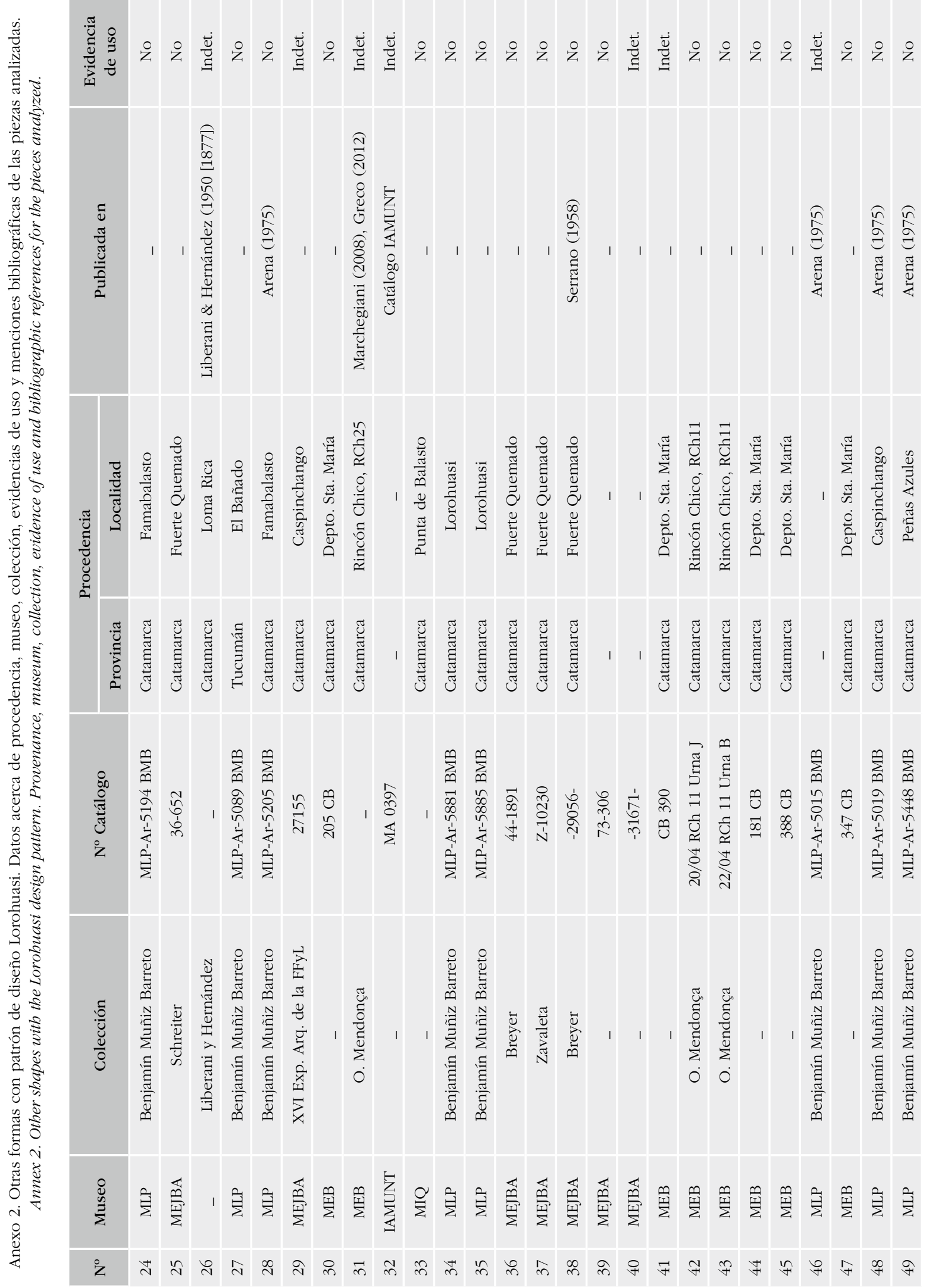




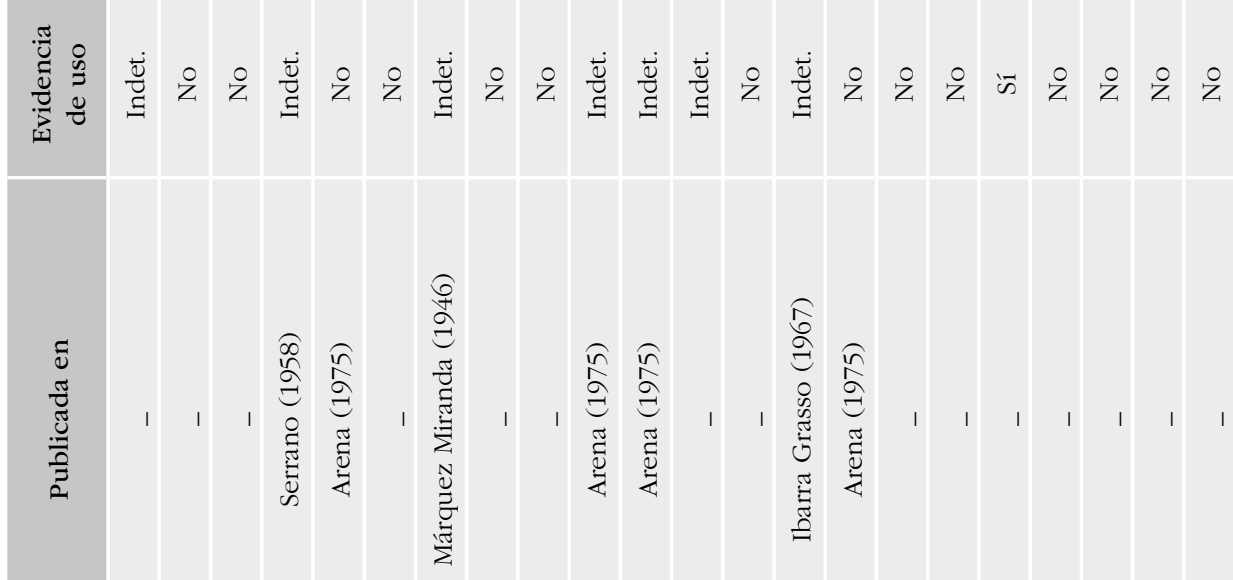

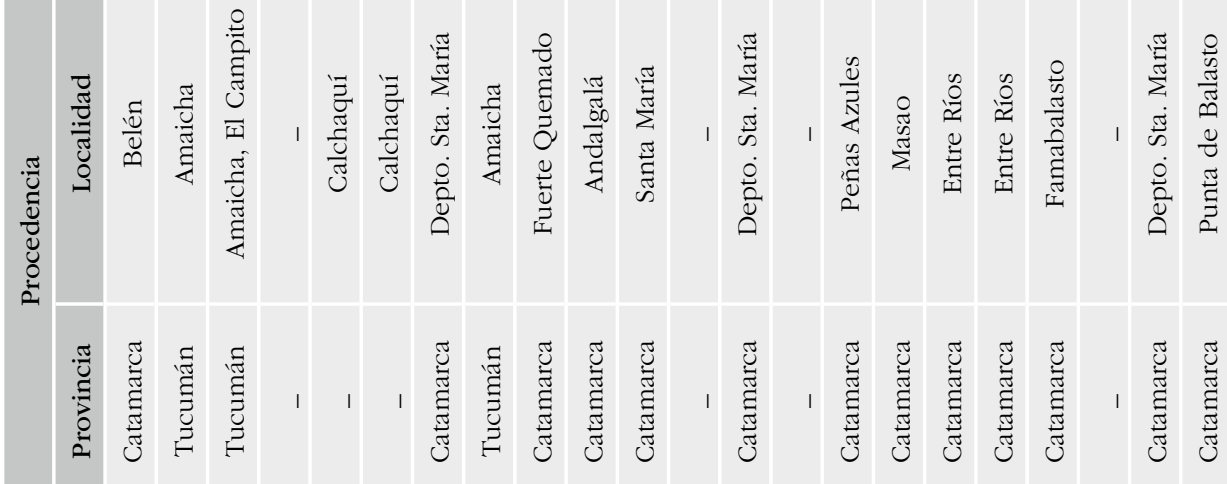

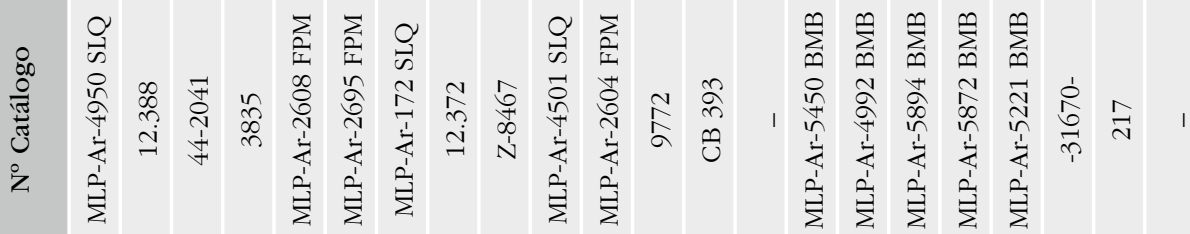

窇

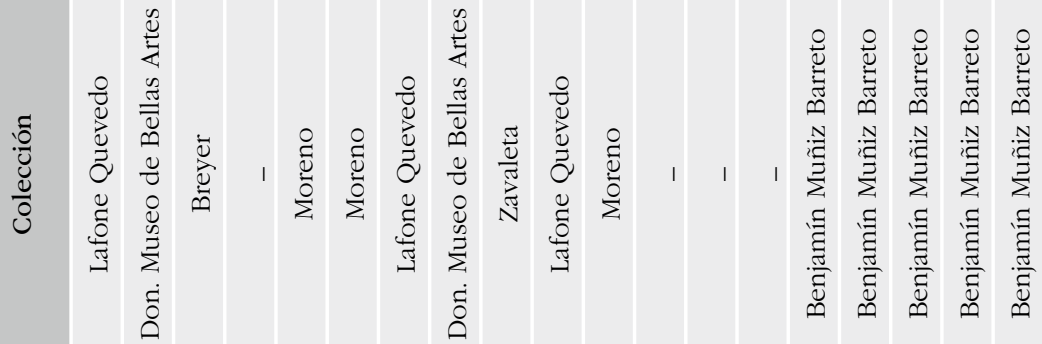

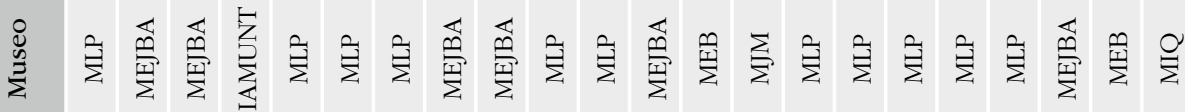

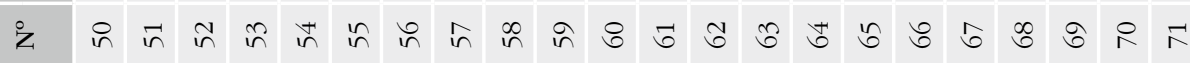




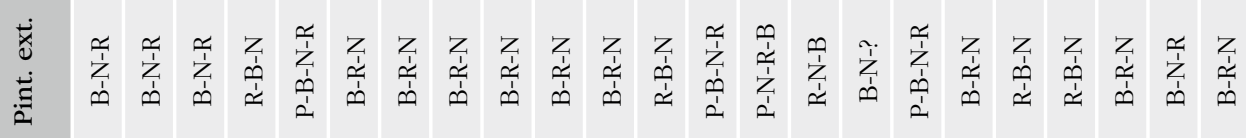

$$
\begin{aligned}
& \text { 䍃 H H }
\end{aligned}
$$

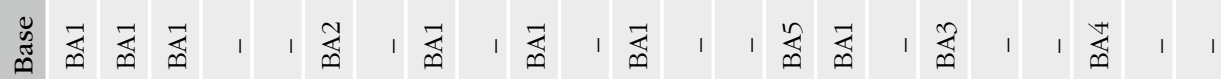

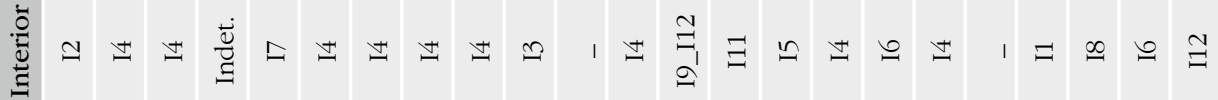




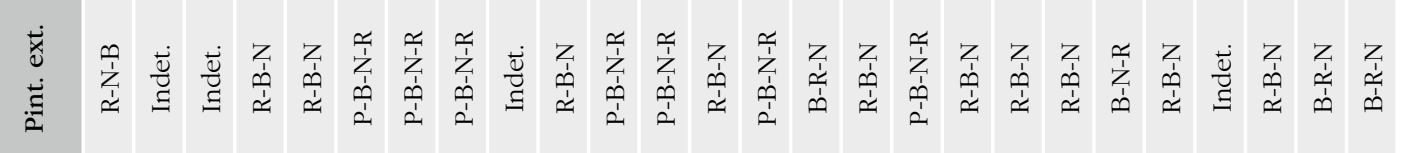

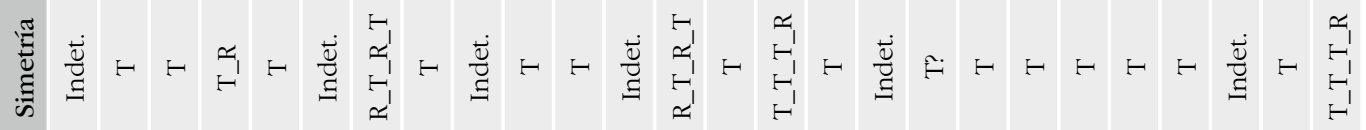

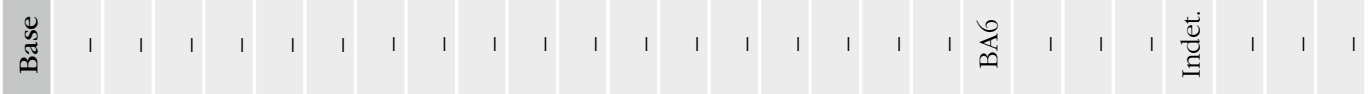

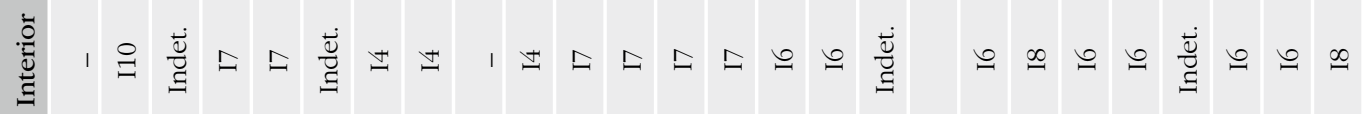

$$
\begin{aligned}
& \text { 离 }
\end{aligned}
$$

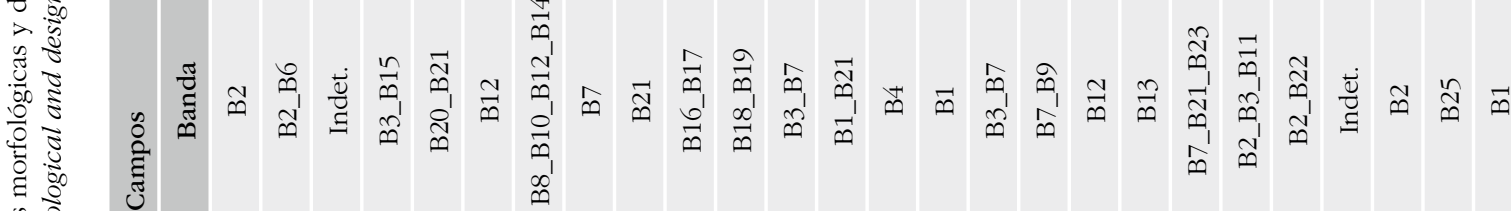$$
\text { 苞 }
$$$$
\text { 要 }
$$$$
\text { : }
$$$$
\text { ช. 50 }
$$$$
\text { 告 }
$$ 


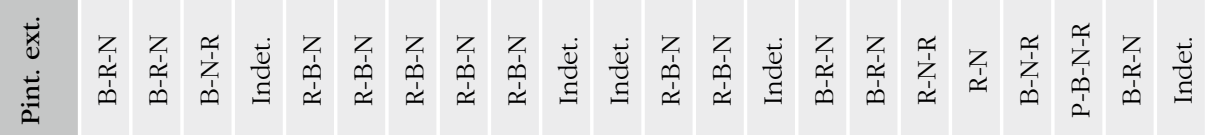

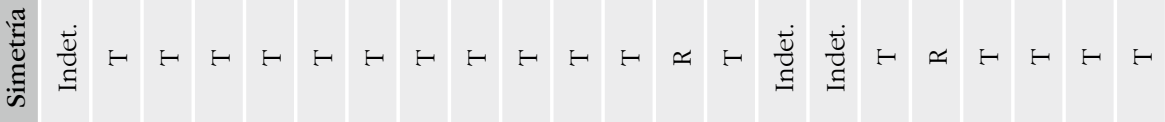

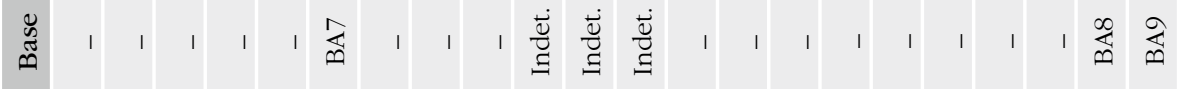

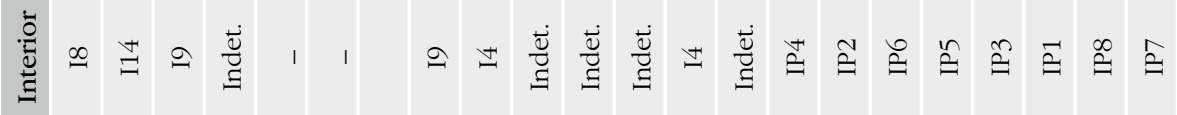

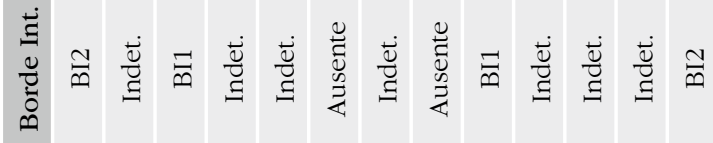

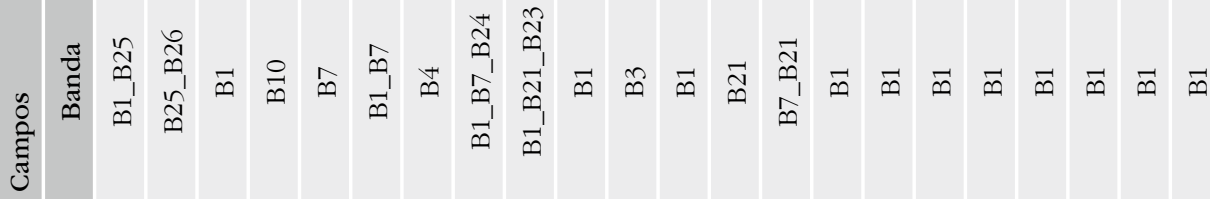

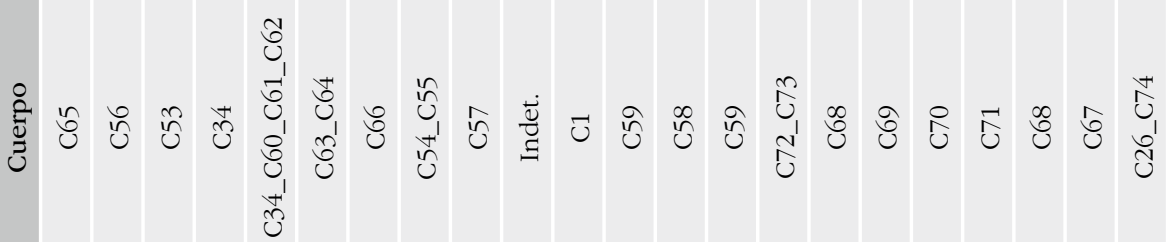

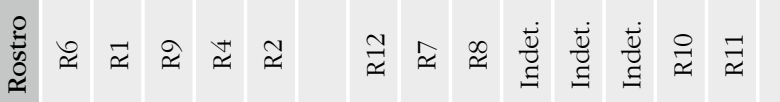

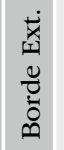

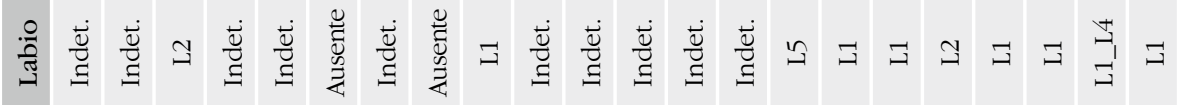

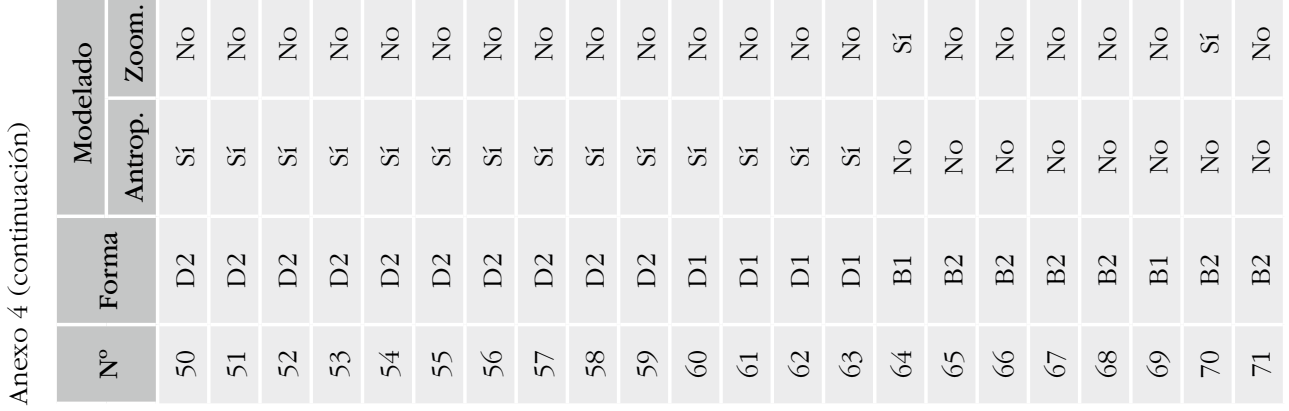




\section{NOTAS}

1 La época histórica que en la arqueología del Noroeste Argentino denominamos Período Tardío o de los Desarrollos Regionales, corresponde al Período Intermedio Tardío según los esquemas de la arqueología andina en Perú, sur de Bolivia y norte de Chile (siglos x a xv).

2 El trabajo se enmarca en el proyecto de la Carrera del Investigador Científico CONICET de la primera autora. Ha contado con el financiamiento del Proyecto Joven Investigador UBACyT 200201003000642011-2014 y con el apoyo de los proyectos PICT 0113 y PIP 0311

3 A lo largo de sus $100 \mathrm{~km}$ se conocen en la actualidad para el valle de Yocavil 15 grandes pukaras.

${ }^{4}$ En un artículo de reciente publicación (Palamarczuk et al. 2014) hemos propuesto una revisión tipológica de las urnas San José y hemos repasado brevemente la historia de las categorías tipológicas de las alfarerías de inicios del Período Tardío en Yocavil.

5 Arena (1975) llamó a estas variantes Peñas Azules Tricolor, Peñas Azules Antropomorfo, Grupo X y Grupo Y. Destacó afinidades estilísticas entre estos tipos, el Hualfín y el Santa María Tricolor.

${ }^{6}$ A diferencia del grupo de los sistemas llamados glotográfi$\cos$ que reproducen segmentos del flujo de habla y constituyen dispositivos gráficos para representar una lengua.

${ }^{7}$ Aquí adaptamos la noción de valor del signo desarrollada por Saussure para los signos lingüísticos a nuestro caso, donde tratamos con signos gráficos. El valor de una palabra está dado por su sentido, pero también por su contraste con otras. Debido al carácter lineal del lenguaje existen relaciones secuenciales entre las palabras, llamadas sintagmáticas. Otro tipo de relaciones remiten a asociaciones con otras palabras no articuladas, que residen en la memoria, basadas en forma y significado, son las relaciones paradigmáticas. Estas clases de relaciones pueden indagarse también en el funcionamiento de los sistemas de signos gráficos

${ }^{8}$ En total se relevó un conjunto que supera los 600 ejemplares. Los museos visitados son: Museo Etnográfico "Juan B. Ambrosetti", Buenos Aires (MEJBA); Museo de La Plata, La Plata, Buenos Aires (MLP); Museo Arqueológico Provincial "Eric Boman", Santa María Catamarca (MEB) y Museo "Inti Quilla", Punta de Balasto, Catamarca (MIQ). Las ilustraciones en bibliografía permitieron incluir piezas del Instituto de Antropología y Museo de la Universidad Nacional de Tucumán, Tucumán (IAMUNT); Museo "Julio Marc", Paraná Entre Ríos (MJM); Museo Arqueológico Provincial "CondorHuasi", Belén, Catamarca; Museo "Adán Quiroga”, Catamarca; Ethnologisches Museum, Viena; Museo de la Cancillería, Buenos Aires.

${ }^{9}$ Sobre la base de la formalización de patrones de diseño en el conjunto San José (tinajas) definimos variantes a las que llamamos: Lorohuasi, Entre Ríos, Negativos y sapitos, Peñas Azules, Shiquimil (Cordón punteado, Dameros, Ondas, Reticulado, Tricolor, Triángulos-Hualfín) (Palamarczuk et al. 2014). Incluimos también en nuestra base de datos piezas de estilos Rincón y Loma Rica, afines al universo estilístico Santa María pero que presentan interesantes cruces estilísticos con las vasijas San José

${ }^{10}$ La pieza 4270 se aparta de la tendencia general mencionada y corresponde a una miniatura, sus dimensiones son: $13 \mathrm{~cm}$ de altura y $20,5 \mathrm{~cm}$ de diámetro.

11 Algunas de estas piezas serían las que Perrotta y Podestá (1975) llaman "Bordo", no obstante la correspondencia no es completamente segura, ya que su descripción no es detallada.

12 Incluyendo casos donde la pieza posee baño rojo completo, otras donde este se limita a los campos y otras donde la pintura roja se aplicó por fuera de los motivos pintados en negro. Un caso excepcional por el uso de los colores es la tinaja de la figura 8, MEJBA 029056, donde tanto bandas como campos son rojos y se delinearon trazos blancos.

13 En todas las formas es una constante que las bandas rojas no contengan diseños.

${ }^{14}$ Una excepción a esta pauta es el uso de tinajas rotas invertidas como tapa.
15 En especial, aquellas incluidas en su grupo "Peñas Azules Tricolor".

${ }^{16}$ El gráfico sintetiza nuestra propuesta clasificatoria a partir de los patrones mayoritarios. El tamaño de los círculos expresa una relación aproximada de frecuencia. Intencionalmente dibujamos los círculos con línea punteada para dar cuenta de cierta "permeabilidad" o capacidad integradora entre variantes, sobre la base de puntos compartidos.

${ }^{17}$ Este patrón (Peñas Azules) carece de las bandas frontales. Aparece en las vasijas descritas por Arena (1975) como Peñas Azules Antropomorfo y algunas Grupo X. Fuera del ámbito de Yocavil, las urnas Hualfín, de marcada afinidad morfológica con San José, también pueden tener figuración antropomorfa modelada. Del mismo modo, las ollas Rincón y Loma Rica, de mayor afinidad al universo Santa María, también poseen figuración antropomorfa modelada y pintada.

\section{REFERENCIAS}

Álvarez Larrain, A.; M. S. Grimoldi \& V. PalamarczuK, 2012. Un hallazgo funerario fortuito en Entre Ríos, provincia de Catamarca. Bioarqueología y estilos alfareros de inicios del Período Tardío en Yocavil. Revista Arqueología 18: 11-37, Buenos Aires.

Ambrosetti, J. B., 1896. El símbolo de la serpiente en la alfarería funeraria de la región calchaquí. Boletín del Instituto Geográfico Argentino XVII: 3-14, Buenos Aires.

Ambrosetti, J. B., 1899. Notas de arqueología Calchaquí (continuación). Boletín del Instituto Geográfico Argentino XX: 253-302, Buenos Aires.

Arena, M. D., 1975. Arqueología de Campo de Fraile y aledaños (Valle del Cajón, Dto. Santa María, Catamarca). Actas y Trabajos I Congreso Nacional de Arqueología Argentina, A. Austral, M. D. Arena \& A. R. González, Eds., pp. 43-96, Buenos Aires.

ARkush, E., 2009. Pukaras de los Collas: Guerra y poder regional en la cuenca norte del Titicaca durante el Período Intermedio Tardío. Andes 7: 463-479, Arequipa.

Arnheim, R., 1985 [1969]. El pensamiento visual. Buenos Aires: EUDEBA.

ARnheim, R., 1987 [1957]. Arte y percepción visual. Buenos Aires: EUDEBA.

Ataliva, V. H., 2000. Nota sobre dualidad simbólica en Aguada. Un caso de estudio: La túnica hallada en San Pedro de Atacama, Chile. Estudios Atacameños 20: 67-75

Ávila, F., 2008. Un universo de formas, colores y pinturas: Caracterización del estilo alfarero Yavi de la puna nororiental de Jujuy. Intersecciones en Antropología 9: 197-212, Buenos Aires.

ÁvilA, F., 2011. Arqueología policroma: El uso y la elección del color en expresiones plásticas. Boletín del Museo Chileno de Arte Precolombino 16 (2): 75-88.

Balesta, B., 2000. La significación en la funebria de La Ciénaga. Tesis doctoral, Facultad de Ciencias Naturales y Museo, Universidad Nacional de La Plata.

Bennett, W. C.; E. F. Bleiler \& F. H. Sommer, 1948. Northwest Argentine Archaeology. Publications in Anthropology 38. New Haven: Yale University.

Bregante, O., 1926. Ensayo de clasificación de la cerámica del Noroeste argentino. Buenos Aires: Editorial Ángel Estrada y Cía.

Bugliani, M. F., 2004. Formas y recursos estilísticos para la representación humana durante el Formativo en el Valle de Santa María. Acta Americana 12 (1): 79-88, Michigan.

Caviglia, S. E., 1985 Ms. Las Urnas para Niños de los Valles Yocavil y Calchaquí: su reinterpretación sobre la base de un enfoque gestáltico. Trabajo final para el Seminario de Arqueología I, Facultad de Filosofía y Letras, Universidad de Buenos Aires.

Caviglia, S. E., 2002. El arte de las mujeres aónik'enk y gününaküna - kayguajenk o kaygütrruj (las capas pintadas). Relaciones de la Sociedad Argentina de Antropología XXVII: 41-69, Buenos Aires. 
Cereceda, V., 1990. A partir de los colores de un pájaro. Boletín del Museo Chileno de Arte Precolombino 4: 57-104.

Cereceda, V., 2010. Semiología de los textiles andinos: Las talegas de Isluga. Chungara 42: 181-198.

GonZález, A. R., 1950-1955. Contextos culturales y cronología relativa en el área Central del N. O. Argentino (Nota Preliminar). Anales de Arqueología y Etnología XI: 7-32, Mendoza.

GIDDENS, A., 1995 [1984]. La constitución de la sociedad. Bases para la teoría de la estructuración. Buenos Aires: Amorrortu editores.

Greco, C., 2012. Integración de datos arqueológicos, radiocarbónicos y geofísicos para la construcción de una cronología de Yocavil y alrededores. Tesis doctoral, Facultad de Filosofía y Letras, Universidad de Buenos Aires.

Hodder, I., 1982. Theoretical Archaeology: A reactionary view. En Symbolic and Structural Archaeology, I. Hodder, Ed., pp. 1-16. Cambridge: Cambridge University Press.

IBARRA Grasso, D. E., 1967. Argentina indigena \& prehistoria americana. Buenos Aires: TEA.

JACKSON, M., 2012. Moche as visual notation: Semasiographic Elements in Moche Ceramic Imagery. En Their way of writing. Scripts, signs and pictographies in pre-Columbian America, E. Boone \& G. Urton, Eds., pp. 227-250. Washington DC: Dumbarton Oaks.

JERnigan, E. W., 1986. A non-hierarchical approach to ceramic decoration analysis: A southwestern example. American Antiquity 51 (1): 3-20, Washington.

Lecoq, P., 1991. Sel et archaeologue en Bolivie. De quelques problems relatives á l'occupation préhispanique de la cordilléreIntersalar (Sud-Ouest bolivien). Tesis doctoral, Ciencias Humanas, Universidad de París.

Levine, M. H., 1957. Prehistoric Art and Ideology. American Anthropologist 59: 949-964, Arlington.

LibERANI, I. \& R. HERNÁNDEZ., 1950 [1877]. Excursión arqueológica en los Valles de Santa María, Catamarca, 1877. Publicación $\mathrm{N}^{\circ}$ 563. Tucumán: Universidad Nacional de Tucumán.

LlamaZAReS, A. M., 1989. A semiotic approach in rock art analysis. En The Meaning of Things, I. Hodder, Ed., pp. 242-248. London: Unwin Hyman.

LlamaZAReS, A. M., 2011. Metáforas de la dualidad en los Andes: Cosmovisión, arte, brillo y chamanismo En Las imágenes precolombinas: Reflejo de saberes, Instituto de Investigaciones Filológicas, Centro de Estudios Mayas, Eds., pp. 455-482. México, D. F.: Universidad Nacional Autónoma de México, Universidad Autónoma de Barcelona.

Márquez Miranda, F., 1946. Los Diaguitas. Inventario patrimonial arqueológico y paleo-etnográfico. Extracto de la Revista del Museo de La Plata (Nueva serie), T. III, Sección Antropología, Instituto del Museo, Universidad Nacional de La Plata.

MARTEL, A. \& S. GIRAUDO, 2014. Semiótica de la imagen en arqueología: El caso de los "escutiformes". Revista Chilena de Antropología Visual 24: 21-45, Santiago.

McCormac, F. G.; A. G. Hogg, P. G. Blackwell, C. E. Buck, T. F. G. Higham \& P. J. Reimer, 2004. ShCal04 Southern Hemisphere Calibration, 0-11.0 Cal Kyr BP. Radiocarbon 46 (3): 10871092, Tucson

NASTRI, J. H., 2008. La figura de las largas cejas de la iconografía santamariana. Chamanismo, sacrificio y cosmovisión calchaquí. Boletín del Museo Chileno de Arte Precolombino 13 (1): 9-34.

Palamarczuk, V., 2011. Un estilo y su época. El caso de la cerámica Famabalasto Negro Grabado del Noroeste Argentino. BAR International Series. Oxford: Archaeopress.
PalamarczuK, V.; A. Álvarez Larrain \& M. S. Grimoldi, 2014. La alfarería de inicios del segundo milenio en Yocavil. El "problema San José" y las tipologías cerámicas. Revista Arqueología 20 (Dossier): 107-134, Buenos Aires.

Perrotta, E. B. \& C. Podestá, 1975. Arqueología de la Quebrada de Shiquimil. Actas y trabajos del I Congreso Nacional de Arqueología Argentina, A. Austral, M. D. Arena \& A. R. González, Eds., pp. 405-422, Buenos Aires.

Podestá, C. \& E. B. Perrotta, 1973. Relaciones entre culturas del Noroeste argentino. San José y Santa María. Antiquitas 17: 6-15, Buenos Aires.

Preucel, R. \& A. BAuer, 2001. Archaeological pragmatics. Norwegian Archaeological Review 34: 85-96. Oslo.

Puente, V. \& L. Quiroga, 2007. Percepción de la forma, variabilidad del conjunto estilístico Belén (Colección Schreiter). Mundo de antes 5: 157-186, Tucumán.

Quiroga, A., 1899. El simbolismo de la cruz y el falo en Calchaquí. Boletín del Instituto Geográfico Argentino X, cuaderno 7 a 12, Buenos Aires.

Rocchietti, A. M., 2009. Arqueología del arte. Lo imaginario y lo real en el arte rupestre. Revista del Museo de Antropología 2: 23-38, Córdoba.

SAMPSON, G., 1985. Writing Systems, a Linguistic Introduction. Stanford: Stanford University Press.

SAussure, F. DE, 1984 [1913]. Curso de lingüística general. Madrid: Alianza.

Serrano, A., 1958. Manual de la cerámica indígena. Córdoba: Editorial Assandri.

Scattolin, M. C., 2006. De las comunidades aldeanas a los curacazgos en el Noroeste argentino. Boletín de Arqueología PUCP 10: 357-395, Lima.

SHEPARD, A., 1957. Ceramics for the Archaeologist. Publication 609. Carnegie Institution of Washington.

Tarragó, M. N., 2011. Poblados tipo pukara en Yocavil. El plano de Rincón Chico 1 (Catamarca, Argentina). Estudios sociales del NOA, nueva serie, 11: 33-61, Tilcara.

Tartusi, M. \& V. Núñez Regueiro, 2003. Procesos de interacción entre poblaciones de los valles intermontanos del Noroeste argentino y las del piedemonte. En Local, Regional, Global: prebistoria, protohistoria e bistoria en los Valles Calchaquies. Anales Nueva Época 6, P. Cornell \& P. Stenborg, Eds., pp. 43-62. Gotemburgo: Universidad de Gotemburgo.

Thompson, E. P., 2000. Agenda para una historia radical. Barcelona: Crítica.

Uribe, M.; AdÁn, L. \& Agüero, C., 2004. Arqueología de los períodos Intermedio Tardío y Tardío de San Pedro de Atacama y su relación con la cuenca del río Loa. Chungara 36: 943-956.

Velandia, C., 2005. Iconografía funeraria en la cultura Santa María, Argentina. Ibagué: Universidad de Tolima.

Voloshinov, V., 1976. El signo ideológico y la filosofía del lenguaje. Buenos Aires: Nueva Visión.

Weiser, V., 1921 Ms. Cuadernos y diarios de campo de la III expedición Benjamín Muñiz Barreto.

Weiser, V. \& F. Wolters, 1922-1924 Ms. Cuadernos y diarios de campo de las IV y VI expediciones Benjamín Muñiz Barreto.

WeBer, R., 1981. An analysis of Santa María urn painting and its cultural implications. Fieldiana Anthropology 2: 1-32, Chicago.

Wynvedit, F., 2007. La estructura de diseño decorativo en la cerámica Belén. Boletín del Museo Chileno de Arte Precolombino 12 (2): 49-67. 
